\title{
Super Cooled Large Droplet Analysis of Several Geometries Using LEWICE3D Version 3
}

Colin S. Bidwell

Glenn Research Center, Cleveland, Ohio 


\section{NASA STI Program . . . in Profile}

Since its founding, NASA has been dedicated to the advancement of aeronautics and space science. The NASA Scientific and Technical Information (STI) program plays a key part in helping NASA maintain this important role.

The NASA STI Program operates under the auspices of the Agency Chief Information Officer. It collects, organizes, provides for archiving, and disseminates NASA's STI. The NASA STI program provides access to the NASA Aeronautics and Space Database and its public interface, the NASA Technical Reports Server, thus providing one of the largest collections of aeronautical and space science STI in the world. Results are published in both non-NASA channels and by NASA in the NASA STI Report Series, which includes the following report types:

- TECHNICAL PUBLICATION. Reports of completed research or a major significant phase of research that present the results of NASA programs and include extensive data or theoretical analysis. Includes compilations of significant scientific and technical data and information deemed to be of continuing reference value. NASA counterpart of peer-reviewed formal professional papers but has less stringent limitations on manuscript length and extent of graphic presentations.

- TECHNICAL MEMORANDUM. Scientific and technical findings that are preliminary or of specialized interest, e.g., quick release reports, working papers, and bibliographies that contain minimal annotation. Does not contain extensive analysis.

- CONTRACTOR REPORT. Scientific and technical findings by NASA-sponsored contractors and grantees.
- CONFERENCE PUBLICATION. Collected papers from scientific and technical conferences, symposia, seminars, or other meetings sponsored or cosponsored by NASA.

- SPECIAL PUBLICATION. Scientific, technical, or historical information from NASA programs, projects, and missions, often concerned with subjects having substantial public interest.

- TECHNICAL TRANSLATION. Englishlanguage translations of foreign scientific and technical material pertinent to NASA's mission.

Specialized services also include creating custom thesauri, building customized databases, organizing and publishing research results.

For more information about the NASA STI program, see the following:

- Access the NASA STI program home page at http://www.sti.nasa.gov

- E-mail your question via the Internet to help@ sti.nasa.gov

- Fax your question to the NASA STI Help Desk at $443-757-5803$

- Telephone the NASA STI Help Desk at 443-757-5802

- Write to: NASA Center for AeroSpace Information (CASI) 7115 Standard Drive Hanover, MD 21076-1320 


\section{Super Cooled Large Droplet Analysis of Several Geometries Using LEWICE3D Version 3}

Colin S. Bidwell

Glenn Research Center, Cleveland, Ohio

Prepared for the

Atmospheric and Space Environments Conference

sponsored by the American Institute of Aeronautics and Astronautics

Toronto, Ontario, Canada, August 2-5, 2010

National Aeronautics and

Space Administration

Glenn Research Center

Cleveland, Ohio 44135 


\section{Acknowledgments}

The author would like to gratefully acknowledge Linda Hedges and Abdi Khodadoust of the Boeing Airplane Company for providing the flow solutions for the trap wing CFD++ and multi-element INS2D examples and Edward Shipley of the Cessna Aircraft Company for providing the flow solutions for the DLR-F4 UNS3D example.

Trade names and trademarks are used in this report for identification only. Their usage does not constitute an official endorsement, either expressed or implied, by the National Aeronautics and Space Administration.

Level of Review: This material has been technically reviewed by technical management.

Available from

NASA Center for Aerospace Information 7115 Standard Drive

Hanover, MD 21076-1320
National Technical Information Service 5301 Shawnee Road Alexandria, VA 22312

Available electronically at http://www.sti.nasa.gov 


\title{
Super Cooled Large Droplet Analysis of Several Geometries Using LEWICE3D Version 3
}

\author{
Colin S. Bidwell \\ National Aeronautics and Space Administration \\ Glenn Research Center \\ Cleveland, Ohio 44135
}

\begin{abstract}
Super Cooled Large Droplet (SLD) collection efficiency calculations were performed for several geometries using the LEWICE3D Version 3 software. The computations were performed using the NASA Glenn SLD splashing model which has been incorporated into the LEWICE3D Version 3 software. Comparisons to experiment were made where available. The geometries included two straight wings, a swept 64A008 wing tip, two high lift geometries, and the generic commercial transport DLR-F4 wing body configuration. In general the LEWICE3D Version 3 computations compared well with the 2D LEWICE 3.2.2 results and with experimental data where available.
\end{abstract}

\section{Nomenclature}

$\begin{array}{ll}\text { AOA } & \text { angle-of-attack } \\ \text { AAOA } & \text { aircraft angle-of-attack } \\ C_{p} & \text { pressure coefficient } \\ \mathrm{c} & \text { chord } \\ \mathrm{d} & \text { droplet diameter, } \mu \mathrm{m} \\ \mathrm{K}_{\mathrm{L}} & \text { LEWICE splashing parameter } \\ \text { LWC } & \text { Liquid Water Content, g/m } \\ \text { MVD } & \text { Median Volume Diameter }\end{array}$

\section{Introduction}

Over the last several years work has been ongoing to develop tools to analyze aircraft configurations subjected to Super-Cooled Large Droplet (SLD) conditions (Ref. 1). These conditions, which are outside the FAA Appendix C (Ref. 2) certification envelope have been responsible for several aviation accidents. New certification rules are pending which will require aircraft to fly safely through these conditions. These new rules will generate new requirements for aircraft ice protection system design and certification and for the tools which aid in these processes.

One of the major challenges in developing tools for SLD condition has been the quantification of the effect of splashing of large drops. The larger drops contained in the SLD environment (>50 $\mu \mathrm{m})$ carry more momentum and arrive at higher speeds at the aircraft surface then the smaller drops defined within the Appendix C envelope. Surface tension for the large SLD drops is not sufficient to hold the drops together under the high impact forces as it is for the smaller drops $(\approx 20 \mu \mathrm{m})$, which results in droplet breakup and splash. Droplet breakup up and splash can result in a substantial amount of mass being ejected from the surface.

Ignoring the effects of splashing for SLD conditions in a computational simulation can result in an over-prediction of collection efficiency. This over-prediction, although conservative, can in many cases yield intractable designs. For this reason, tools which accurately predict the effect of splashing are needed to aid in the design, development and certification of aircraft systems for SLD conditions. 
NASA Glenn has incorporated SLD splashing models into several of their icing tools to aid in the design, development, and certification of aircraft ice protection systems. These tools include the twodimensional (2D) LEWICE 3.2.2 software (Ref. 3), hereafter referred to as LEWICE, and the threedimensional (3D) LEWICE3D V3 software (Ref. 4), hereafter referred to as LEWICE3D. The LEWICE software, which contains the original NASA SLD splashing model, has been previously validated against large droplet collection efficiency data gathered during NASA-Wichita State University (WSU) Icing Research Tunnel (IRT) droplet impingement tests (Ref. 5). The work presented in this paper represents the validation of LEWICE3D with the newly incorporated NASA Glenn SLD model.

Collection efficiency results are presented for two 2D wings, a swept 64A008 wing tip, two high lift models and a generic commercial transport. The wings include an MS-317 (Ref. 6) and an NLF(1)-0414 (Ref. 7). The high lift models include a straight, three element high lift wing model developed by McDonnell Douglas Aerospace (Ref. 8), and the generic trapezoidal high-lift wing (trap wing) developed by NASA (Ref. 9). The DLR-F4 wing body model developed as a CFD test bed was used to represent a commercial transport configuration (Ref. 10). Experimental SLD data was available for the 2D wings and for the three element wing model. No SLD data exists for the trap wing and for the DLR-F4 configuration.

\section{Experiment}

\section{Experimental Apparatus}

The aerodynamic and collection efficiency tests were carried out in the NASA Glenn IRT. The test equipment included the IRT (Fig. 1), the ESCORT data system, a special spray system for the impingement tests (Fig. 2), a laser reflectometer for impingement efficiency data reduction (Fig. 3), blotter strips attached to the models (Fig. 4), and the four test models (Figs. 5(a) to 8(a)).

The IRT facility can provide a range of airspeeds, angles-of-attack, temperatures, liquid water contents (LWC), and drop sizes (Ref. 11). The IRT has a 2.47- by 1.82-m test section with a maximum airspeed of $134 \mathrm{~m} / \mathrm{s}$ (empty tunnel). Angle-of-attack is controlled by a movable turntable to which the models are mounted. A refrigeration system allows year-round testing at temperatures from -29 to $10{ }^{\circ} \mathrm{C}$. The spray system located upstream of the test section can provide a cloud with a range of LWC of 0.25 to $3.0 \mathrm{gm} / \mathrm{m}^{3}$ and a median volumetric droplet diameter (MVD) size range of 12 to $200 \mu \mathrm{m}$.

The ESCORT system was developed at Glenn to aid in storage, processing, and analysis of large amounts of data (e.g. temperature, pressure) produced in various experiments at Glenn Research Center. In this test ESCORT was used to store tunnel total temperature, total pressure, free stream airspeed, surface pressure, produce real time calculations and display pertinent parameters. The storage sequence for each data point was initiated by the researcher in the control room. A separate program was used to do a more complete post run analysis.

The spray requirements for the impingement tests precipitated the need for a different spray system (Fig. 2) than is available in the IRT (Ref. 5). The IRT spray system could not produce the short (2 to $9 \mathrm{sec}$ ), stable sprays (i.e. constant LWC and drop size) required to prevent blotter strip saturation. There were also concerns that the dye would contaminate the IRT spray system. The new system consisted of 16 nozzles and a supply tank located at the IRT spray bar station (Fig. 2). The system featured short supply lines which enabled short, stable sprays.

One unique feature of the current technique is the laser reflectometer used to determine the local collection efficiency (Fig. 3). The device measures the local reflectance of the blotter strip and correlates this to the local collection efficiency (Ref. 5). The device saved considerable time in the data reduction of the blotter strips.

The MS-317 airfoil was designed in the mid 1970s to bridge the gap between low speed and supercritical airfoils for application on general aviation aircraft. The airfoil was designed for a lift coefficient of 0.3 , Reynolds number of 14 million and a Mach number of 0.68 . The IRT MS-317 model 
(Fig. 5(a)) was an unswept, untapered, full span model. The chord was $0.9144 \mathrm{~m}$, and the span was $1.8288 \mathrm{~m}$. The model contained 49 pressure taps located along the wing centerline.

The natural-laminar-flow NLF(1)-0414 wing model was an unswept, untapered, full span model built for the IRT (Fig. 6(a)). The NLF(1)-0414 airfoil was designed in the early 1980s as a medium speed airfoil with low section drag and high maximum lift. The airfoil was designed for a Reynolds number of 10 million, a Mach number of 0.4 , and a lift coefficient of 0.4 with 0.7 c laminar flow on both the upper and lower surfaces. The wing had a chord of $1.2192 \mathrm{~m}$ in. and a span of $1.8288 \mathrm{~m}$. The pressure instrumentation included 124 taps located along the center span of the model.

The swept, tapered NACA 64A008 wing tip represents a typical business jet horizontal tail (Fig. 7(a)). The model had a span of $1.2192 \mathrm{~m}$, a leading edge sweep angle of $29.1^{\circ}$, a root chord of $1.1621 \mathrm{~m}$, a taper ratio of 0.62 and a cylindrical tip. The model had two rows of 31 pressure taps at the 50 and 90 percent span stations.

The multi-element IRT model was full span $(1.8288 \mathrm{~m})$ and had a nested chord length of $0.9144 \mathrm{~m}$ (Fig. 8(a)). The aluminum model had three elements (slat, main element, and flap) and contained 128 pressure taps. The taps were located along the model centerline and along two span-wise rows on the upper surface and on one span-wise row on the lower surface.

\section{Experimental Testing}

Two types of testing were done in the IRT: aero-performance and impingement efficiency testing. The aero-performance testing involved the use of the NASA Glenn ESCORT system to take surface pressure measurements. The impingement efficiency testing involved the use of a dye tracer technique to measure the location and amount of water impinging on the model.

Surface pressures were measured on the wing models using the ESCORT system. Pressure measurements were taken at an airspeed of $75 \mathrm{~m} / \mathrm{s}$, at angles-of-attack of $0^{\circ}$ and $8^{\circ}$ for the MS-317 model, $0^{\circ}$ and $8^{\circ}$ for the NLF(1)-0414 model, $0^{\circ}$ and $6^{\circ}$ for the swept $64 \mathrm{~A} 008$ wing model, and $0^{\circ}$ for multi-element model. These pressure measurements were used to generate coefficient of pressure distributions for the comparisons presented in this paper.

The experimental technique used in the current tests to determine the impingement characteristics of a body is one that was developed in the early 1950s with a few modifications (Ref. 5). The technique involved spraying a dye-water solution of a known concentration onto a model covered with blotter strips. Figure 4 shows a typical blotter installation for the swept 64A008 wing. The result was that the local impingement efficiency on the blotter strips was related to the variation in color intensity. That is, the areas of higher impingement rate are darker and those with lower impingement rate are lighter.

Several steps were necessary to prepare the IRT for impingement testing. The specially designed spray system had to be installed and adjusted to produce a uniform cloud. The local LWC had to be measured at each blotter strip location (with the tunnel empty) for every spray and tunnel condition to account for any cloud non uniformity that existed after the final spray adjustment. After these adjustments and measurements were made the model was inserted and tested. Each test point was repeated four times to obtain a measure of the repeatability (Ref. 8).

A typical test point involved several steps. The model was cleaned and blotter strips were attached at points of interest. The spray was then made, the blotter strips were removed, and labeled, and the model was cleaned and made ready for the next condition.

The models were tested for several MVD drop sizes (11-, 21-, and 92- $\mu \mathrm{m})$ and angles-of-attack. The work in this paper will focus on the $92 \mu \mathrm{m}$ MVD drop size case which is indicative of an SLD condition. Collection efficiency data was taken at an airspeed of $80 \mathrm{~m} / \mathrm{s}$, a static temperature of $277 \mathrm{~K}$, and static pressure of $94,540 \mathrm{~Pa}$. The angle-of attacks tested were $0^{\circ}$ and $8^{\circ}$ for the MS-317 model, $0^{\circ}$ and $8^{\circ}$ for the NLF(1)-0414 model, $0^{\circ}$ and $6^{\circ}$ for the swept 64A008 wing model, and $0^{\circ}$ for the multi-element model. The drop size tests were repeated four times for each condition to generate a statistical average.

Measurements of the spray cloud drop distributions were made using several drop size measuring probes. The NASA Glenn Forward Scattering Spectrometer Probe (FSSP) and the Optical Array Probe 
(OAP) were used to measure the droplet concentrations and MVD's for the various spray conditions. These measurements were used to generate the 10 bin and 27 bin distributions used for the analysis. These distributions are shown in Tables 1 and 2.

\section{Analytical Method}

A variety of 2D and 3D flow and icing codes were used for the analysis. Some of the flow solutions were generated at NASA Glenn while others were provided by industry. The LEWICE and LEWICE3D programs were used to generate the collection efficiency results.

\section{CFD++}

The CFD++ flow solver was developed at Metacomp Technologies (Refs. 12 and 13). CFD++ is a finite volume, unsteady, Navier-Stokes flow solver which can accommodate unstructured, hybrid, and overset grids and can generate flow solutions for flow regimes covering incompressible to supersonic. The solver can handle a variety of flow problems such as high speed reacting/non reacting flows, multi phase flow, conjugate heat transfer and electrostatics. The software supports a number of popular turbulence models and can be run on a variety of parallel platforms including, Linux, Unix and Windows.

\section{PMARC}

PMARC is a first order 3D potential flow panel code (Ref. 14). Geometries are represented as quadrilaterals which have constant doublet and source distribution. The formulation used in PMARC results in a solution that is second order accurate allowing for accurate flow solutions with fewer panels and less CPU time than other first order methods. The disadvantage of this method is that because a numerical differentiation is used to generate the velocity distribution careful panel modeling is required to prevent numerical errors. The code can generate solutions for internal and external compressible flows and can handle very large problems ( 10,000 panels).

\section{USM3D}

USM3D is a 3D compressible, unstructured, Navier-Stokes flow solver (Ref. 15). The solver developed by Frink is a tetrahedral, cell centered, finite volume based flow solver. The parallel solver which can solve steady or unsteady cases employs local time stepping and Residual smoothing to aid in convergence.

\section{NSU3D}

NUS3D is a 3D unstructured, compressible, Navier-Stokes flow solver (Ref. 16). The parallel solver developed by Mavriplis employs a Roe-Rieman solver and supports multi-grid and low Mach number pre-conditioning to aid convergence.

\section{INS2D}

INS2D is a 2D, multi-block, structured Navier-Stokes flow solver which supports overset grids (Ref. 17). The code developed by Rogers can handle steady and unsteady problems.

\section{LEWICE 3.2.2}

LEWICE 3.2.2 is a 2D, multi-time step ice accretion code (Ref. 3). The code uses a 2D panel code to generate a new flow-field at each time step. The latest version of the software enables the analysis of SLD 
icing conditions and of hot air and electro-thermal anti-icing systems. LEWICE performs its analysis for 2D geometries in minutes on a desktop PC, allowing the user to run several parameter studies for design purposes. The ice shape predictions have been validated against a wide variety of experimental conditions.

\section{LEWICE3D Version 3}

The LEWICE3D grid based code incorporates droplet trajectory, heat transfer and ice shape calculation into a single computer program (Ref. 4). The code can handle generic multi-block structured grid based flow solutions, unstructured grid based flow solutions, simple Cartesian grids with surface patches, and adaptive grids with surface patches. The latter two methods allow the use of generic panel code input which, when combined with LEWICE3D, is a computationally efficient method for generating ice shapes. The code can handle overlapping and internal grids and can handle multiple planes of symmetry. Calculations of arbitrary streamlines and trajectories are possible. The code has the capability to calculate tangent trajectories and impingement efficiencies for single droplets or droplet distributions using a standard area-based collection efficiency method or a Monte Carlo based method. Ice accretions can be calculated at arbitrary regions of interest in either a surface normal or tangent droplet trajectory direction. The program can run on a variety of single processor and parallel computers, including Unix, Linux and Windows.

Version 3 of the LEWICE3D software, which incorporates several new features, was used for the analysis. These features include a new particle splash and bounce algorithm, a new geometry handling scheme which allows complex mirroring, transformation and relative motion of input grid blocks and a new algorithm which calculates block to block collection efficiencies. These new additions will enable users to analyze SLD conditions and to calculate collection efficiency with particle splash and bounce effects through turbo-machinery.

\section{Configuration}

The six models chosen for the analysis encompassed a variety of models and flow solution strategies. The LEWICE code, which has its own internal flow solver, uses a 2D Hess-Smith based panel code. The LEWICE3D code, which requires a grid based flow solution, employed solutions from the USM3D, INS2D, CFD++ and PMARC. The 3D solutions involved various approximations and boundary conditions.

The panel model for the LEWICE MS-317 model contained 108 elements while that for the LEWICE NLF(1)-014 model contained 105 elements.

The USM3D flow solver was used to generate flow solutions for the MS-317 and NLF(1)-0414 LEWICE3D analysis. The flow solutions were inviscid and mirror boundary conditions were used at the wing tips. The mirrored wing tip boundary condition was used to generate an extruded, 2D flow-field approximation. The grids for the MS-317 and NLF(1)-0414 models were generated using the GridTool and VGRID programs (Refs. 18 and 19) distributed in the Tetruss Package. The MS-317 grid model contained 5,153,753 tetrahedrons and 909,708 grid points. The NLF(1) grid contained 7,264,130 tetrahedron and 1,273,226 grid points. The surfaces for the MS-317 and NLF(1)-0414 models are shown in Figures 5(b) and 6(b) respectively.

The swept 64A008 wing flow model was generated using the PMARC/ICEGRID panel code interface for LEWICE3D. The ICEGRID program (Ref. 20) was used to generate a 3D "oct-tree” type grid about the wing and the PMARC code was used to calculate velocities at the grid nodes. PMARC was executed using a steady, isolated flow with a $y=0$ plane of symmetry (Fig. 7(b)). The swept 64A008 panel model contained 2,303 panels and the grid contained 216,708 nodes.

Two flow solver methodologies were employed for the multi-element wing. The INS2D program was used to generate an isolated 2D incompressible, viscous flow solution for the wing. The 2D, structured, multi-block, chimera based solution was extruded to generate a 3D solution. The INS2D extruded, 3D 
grid contained four blocks and 725,706 grid points. The USM3D flow solver was also used to generate 3D flow solutions for the analysis. The USM3D flow solutions were viscous, compressible and the flow model included the IRT test section walls. Separate grid models were developed for the $0^{\circ}$ and $-1.5^{\circ}$ angle-of-attack solutions. The $0^{\circ}$ angle-of-attack grid model contained 53,268,615 tetrahedrons and $9,164,492$ grid points. The $-1.5^{\circ}$ angle-of-attack grid model contained 52,814,552 tetrahedrons and $9,084,829$ grid points. The surface model for the INS2D model is shown in Figure 8(b) while that for the USM3D model is shown in Figure 8(c).

The CFD++ unstructured flow solver was used to generate the flow solution for the trap wing. The CFD++ solution was generated at a Reynolds Number of 8.8 million, a Mach number of 0.23 , and an aircraft-angle-of-attack of $8^{\circ}$ on a model which had a span of $6.27 \mathrm{~m}$. The airspeed for this case was $70 \mathrm{~m} / \mathrm{sec}$. The half-plane grid contained 3,804,849 nodes, 9,711,808 volume elements and 173,287 surface elements. The volume grid was developed using the AFLR3 grid generation program (Ref. 21). The surface model for the trap wing is shown in Figure 9.

The DLR-F4 flow solution was generated using the NSU3D flow solver. The half-plane flow solution was inviscid, and incompressible and was generated for an aircraft-angle-of-attack of $0^{\circ}$. The volume grid contained 1,305,296 volume elements and 257,240 nodes. The surface model for the trap wing is shown in Figure 10.

\section{Analysis}

Results from the comparison of measured and predicted pressure distribution and collection efficiency for the models tested in the IRT will be discussed. Results for the trap wing and DLR-F4 Airplane analysis, for which no experimental collection efficiency data exists, will also be discussed.

The coefficient of pressure distribution comparisons for the MS-317 model are shown if Figure 11. The measured values are depicted with the analytical results from the LEWICE and USM3D flow solutions. The angle-of-attack used for both the LEWICE and USM3D flow solutions was that which gave the best comparison to experiment. This was done to reduce the influence of flow-field deficiencies on the calculated collection efficiency results. Deficiencies in the inviscid, 2D nature of the LEWICE and USM3D flow-fields and in flow angularity in the IRT can result in as much as a $2^{\circ}$ difference between the measured turn table angle and the locally predicted angle-of-attack. A $2^{\circ}$ difference in angle-of-attack can cause a significant change in collection efficiency. Because the main intent of this work was to validate the calculation of collection efficiency and not the calculation of flow the adjustment of AOA to generate the best pressure distribution comparisons was considered a reasonable approach. For the $0^{\circ}$ experimental condition the best comparison was at angle-of-attack of $-2.0^{\circ}$ and $-1.85^{\circ}$ respectively for LEWICE and for USM3D. The angle-of-attack for the best comparison for the $8^{\circ}$ experimental data was $6.15^{\circ}$ for both LEWICE and USM3D.

The calculated pressure distributions compare well to each other and to the experimental results for both the $0^{\circ}$ and $8^{\circ}$ angles-of-attack for the MS-317 model. The maximum coefficient of pressure is noticeably higher for the USM3D prediction than for the experimental and LEWICE results for the $8^{\circ}$ case. This is probably because the USM3D flow model had higher resolution near the pressure peak and was therefore able to pick up the pressure peak more accurately. The trailing edge coefficient of pressures are under-predicted for both the $0^{\circ}$ and $8^{\circ}$ cases. This is probably due to viscous effects such as a "thickening" of the trailing edge due to boundary layer growth or trailing edge separation which the inviscid flow solutions do not model.

Collection efficiency results for the MS-317 model are shown in Figures 12 and 13. Results are shown with and without splashing and for both LEWICE and LEWICE3D. From the figures one can see that the collection models for the 3D and 2D codes agree well. The results for the 27 bin distribution and the 10 bin distribution also compare well with the 10 bin distribution for both the $0^{\circ}$ and $8^{\circ}$ angle-ofattack cases verifying that the 10 bin approximation for the SLD distribution is reasonable. Both programs over-predict the peak collection efficiency by about 18 percent for the $0^{\circ}$ and $8^{\circ}$ angle-of-attack cases and over-predict the point at which the collection efficiency goes to zero on both the upper and 
lower surfaces (i.e. impingement limits). One can also see that SLD calculations agree well with the experimental data and that neglecting splashing results in a large over-prediction of the collection efficiency near the impingement limits. The splashing model results in an over-prediction of the impingement limits and an over-prediction in the collection efficiency near the mid span of both the upper and lower impingement regions. The over-prediction is more severe for the higher AOA case and approaches about 30 percent for the lower surface of the model. This over-prediction though only results in about a 5 to 10 percent over-prediction in total collection efficiency (area under the collection efficiency curve) which is much better than the non-splashing result for which the over-prediction is 15 to 20 percent. The splashing result is conservative in that it is an over-prediction but is not overly conservative as is the non-splashing results. One can also see that the LEWICE3D predicted results are slightly larger than the LEWICE results near the impingement limits. This is because a splashing limiter was required by LEWICE3D to keep trajectory integration times reasonable for some particles impacting at shallow angles. This limiter resulted in larger collection efficiencies for LEWICE3D than for LEWICE, which did not require a limiter, near the impingement limits where the impact angles are typically small.

The LEWICE3D splash limiter employed sets the minimum impact angle for a given LEWICE splashing parameter, $\mathrm{K}_{\mathrm{L}}$ (Ref. 22) for which a particle splash can occur. For a small impact angle, which is the angle between the surface and the impacting droplet, the NASA Glenn SLD model yields a small splash angle, which is the angle at which the splashed droplet rebounds from the surface. Small splash angles yield particle positions very close to the body and generate splash velocities nearly parallel to the surface. For large or warped surface cells numerical issues in defining the exact location of the 3D surface can yield erroneous impacts and problematic velocity searches for particles which are very close to the surface. The result being that that the rebounding particles impact within a few integration steps of rebound. This process repeats itself with the particle skipping many times until it has exited the computational domain. Particle "skipping" dramatically increases trajectory integration time and, in general, results in no additional impingement. By employing a splashing limiter the droplet trajectories are terminated at the impact point for shallow impact angles which avoids particle "skipping" thus decreasing particle integration time. This limiter results in more collection at the impact location then if the particle were allowed to splash.

Results for the NLF(1)-0414 model are shown in Figures 14 to 16 . The coefficient of pressure comparisons for the $0^{\circ}$ and $8^{\circ}$ angles-of-attack are shown in Figure 14. As for the MS-317 case the analytical angles-of-attack used were those that gave the best comparison to the experiment pressure distributions. For the $0^{\circ}$ experimental condition the best comparison was at angle-of-attack of $-0.75^{\circ}$ for both LEWICE and for USM3D. The angle-of-attack for the best comparison for the $8^{\circ}$ experimental data was $6.3^{\circ}$ for both LEWICE and USM3D. The analytical pressure coefficients compare well with experiment for the both the $0^{\circ}$ and $8^{\circ}$ cases. The pressure peak predicted is slightly higher than that measured and predicted by LEWICE. This is attributed to the more highly refined surface and to the inviscid nature of the USM3D solution. As for the MS-317 model the trailing edge coefficient of pressures are under-predicted for both the $0^{\circ}$ and $8^{\circ}$ cases. This again is probably due to viscous effects which the inviscid flow solutions do not model.

Collection efficiency results are shown in Figures 15 and 16 with and without splashing and for the both LEWICE and LEWICE3D. From the figures one can see that the collection efficiency models for the 3D and 2D codes agree well. The LEWICE3D non-splashing collection efficiency result shows a region of increased collection near the trailing edge due to the cusped nature of the trailing edge for the $8^{\circ}$ angleof-attack case. The LEWICE and experimental results do not show this region of increased beta probably due to a small difference in the local angle-of-attack between the wind tunnel model and LEWICE models. The results for the LEWICE 27 bin and 10 bin calculations agree for both angles-of-attack. One can also see, as was the case for the MS-317 model, that the SLD calculations agree much better with the experimental data and that neglecting splashing results in a large over-prediction of the collection efficiency near the impingement limits. The collection efficiencies are slightly over-predicted from the mid-span to the trailing edge for both the $0^{\circ}$ and $8^{\circ}$ cases by LEWICE3D due to the impact angle limiter mentioned above. As in the MS-317 case, the splashing model over-predicts the total collection efficiency 
( $<10$ percent) but the over-prediction is much less than that of the standard no-splash model ( $>20$ percent). The splashing model results are conservative but not overly so as was the case for the non-splashing result.

The results for the NACA 64-A008 wing are shown in Figures 17 to 19. Because the model was a 3D swept, tapered wing results are only presented for USM3D and LEWICE3D. Angles-of-attack of $0^{\circ}$ and $6.3^{\circ}$ were used to best simulate the flow for the $0^{\circ}$ and $6^{\circ}$ experimental cases respectively.

The pressure distribution comparisons for the NACA 64A008 wing are shown in Figure 17. The USM3D results compare well with the experimental data except near the pressure peak and at the trailing edge. As was the case for the previous models, the higher resolution of the surface model results in ability to better resolve the pressure peak although this peak is probably over-predicted due to the inviscid nature of the flow solution. The trailing edge coefficient of pressures were under-predicted due to viscous effects not being captured by the inviscid flow model.

The collection efficiency results for the NACA 64A008 wing are shown if Figures 18 and 19. The results for the standard model show a large over-prediction in local and total collection efficiency (> 20 percent). The collection efficiency results for the 10 bin calculation with splashing agrees well with the experimental data ( $<5$ percent). The splashing model over-predicts the peak collection efficiency by about 13 percent for the $0^{\circ}$ and $6^{\circ}$ angle-of-attack cases. For the $6^{\circ}$ case there is an under-prediction of the collection efficiency near the mid-span on the pressure side of the wing and an over-prediction of the collection efficiency near the impingement limits. The impingement limits are also over-predicted for the $6^{\circ}$ angle-of-attack case. The splashing again produces a reasonably conservative result for the overall collected mass.

Pressure and collection efficiency distributions are shown for the multi-element model in Figures 21 to 26. Experimental pressure distributions are shown along with analytical pressure distributions for the INS2D and USM3D based flow solution for several angles-of-attack. The INS2D solution was generated for an angle-of-attack of $0^{\circ}$. The USM3D solutions were generated for $0^{\circ}$ and $-1.5^{\circ}$. The $-1.5^{\circ}$ case was generated to better match the pressure distribution on the slat.

Figures 21 to 23 display the pressure distribution comparisons for the multi-element model. The INS2D results and USM3D computations for $0^{\circ}$ angle-of-attack agree well except near the pressure peak for the main element and flap. The agreement of the USM3D and INS2D solutions at an angle-of-attack of $0^{\circ}$ was considered quite remarkable considering that the INS2D solution was incompressible and that it did not include wall effects. The larger peak value for the main element and flap for the INS2D solution is partly the result of the incompressible assumption for the flow and due to the higher resolution of the INS2D surface grid. The INS2D and USM3D pressure distribution for $0^{\circ}$ angle-of-attack agree well with the experiment for the main element and flap but the comparison for the slat was considered poor. The comparisons imply an over-prediction in local angle-of-attack for the slat and an under-prediction in angle-of-attack for the flap. An attempt was made to improve the agreement by running a USM3D flow solution at an angle-of-attack of $-1.5^{\circ}$. This resulted in better agreement on the slat but poorer comparison for the main element and flap. Because there was no best USM3D flow solution collection efficiency results were generated for both $0^{\circ}$ and $-1.5^{\circ}$ angles-of-attack.

The collection efficiency comparisons for the three element high-lift model are shown in Figures 22 to 24. The non-splashing 27 bin INS2D and 10 bin USM3D based collection efficiency comparison agree well for the angle-of-attack of zero for the slat. The INS2D non-splashing based calculation generates higher collection efficiencies for both the main element and flap than the USM3D based calculation. This is probably due to the higher angle-of-attack realized on these elements for the INS2D solution than for the USM3D solution. It could also be due to the use of the coarser 10 bin distribution used for the USM3D based analysis.

The best agreement for the slat shown in Figure 24 was for the USM3D based flow model at $0^{\circ}$ angle-of-attack with splashing. The results with splashing for this case resulted in an over-prediction of collection efficiency near the lower impingement limit by about 27 percent and an over-prediction of less than 5 percent in total collection efficiency. This result is reasonably conservative and much less 
conservative then the non-splashing results for the $0^{\circ}$ angle-of-attack USM3D solution which had an over-prediction of total collection efficiency of greater than 10 percent.

Collection efficiency results for the main element are presented in Figure 25. The INS2D and USM3D based solutions at $0^{\circ}$ angle-of-attack over-predict the amount and extent of impingement and the number of impingement regions for main element. The experimental data shows two regions of impingement on the lower side of the main element. These include a small region near the stagnation region and a larger one further back. The analytical solutions reflect impingement in three distinct regions one of which is on the upper surface of the main element. It may be that this upper surface impingement region was missed during the experiment because strips were not located there. The best agreement between experiment and analysis occurred for the $-1.5^{\circ}$ angle-of-attack based USM3D solution with splashing. The extent and magnitude of impingement agree well for this case although the aft impingement region occurs further aft for the analytical solution by about $5 \mathrm{~cm}$.

The multi-element flap collection efficiency results are shown in Figure 26. The analytical results under-predicted the amount and extent of impingement and the total collection efficiency for the flap. The total collection efficiency was under-predicted by as much as 30 percent for the flap. This could be due to an under-prediction in the local angle-of-attack by the flow solver which is evident in the coefficient of pressure distribution comparisons for the flap and in the location of the upper impingement limit on the flap. The splashing model did not improve the comparisons for flap. A small amount of re-impingement on the flap resulted in slightly more mass being added for the USM3D $0^{\circ}$ and $-1.5^{\circ}$ angle-of-attack cases but the best agreement was still for the non-splashing INS2D $0^{\circ}$ angle-of-attack bases solution. The lack of agreement for the flap was probably due to flow-field deficiencies. Past experience has shown that if the flow-field matches experiment then the impingement data compares well. Future work needs to be done to generate a better flow simulation for this geometry.

Collection efficiency calculations for the trap wing model are shown in Figures 27 to 31 . No experimental collection efficiency data was available for this geometry. Calculations for a 10 bin distribution were made for a $92 \mu \mathrm{m}$ MVD drop size indicative of an SLD environment and for a single $20 \mu \mathrm{m}$ drop which is more indicative of an Appendix C environment. The $92 \mu \mathrm{m}$ MVD drop case with splashing resulted in about 200 to 500 percent greater total collection efficiency than for the $20 \mu \mathrm{m}$ drop case. The $92 \mu \mathrm{m}$ MVD drop splashing case yielded about 15 to 30 percent less total collection efficiency then the $92 \mu \mathrm{m}$ MVD drop case without splashing for the trap wing elements shown in Figures 28 to 30 . The mass loss for the trap wing is similar to that found for the models above. Evident in Figure 31 are areas near the wing root on the slat and flap which show higher collection efficiencies for the splash model due to the re-impingement of the mass splashed from the nose, slat and main elements.

The DLR-F4 collection efficiency results are presented in Figures 32 to 35. The splashing model results in significant mass loss from the nose, windshield and wing. The overall mass loss due to splashing for the $92 \mu \mathrm{m}$ MVD drop case is about 15 to 30 percent for the wing, nose, and windshield. A small amount of re-impingement on the base of the windshield from the aircraft nose is evident in Figure 33 and 35 (< 5 percent). The $92 \mu \mathrm{m}$ MVD drop case with splashing yielded about 300 percent more mass on the wing and about 800 percent more mass on the nose and windshield than for the $20 \mu \mathrm{m}$ drop case. Areas of higher collection efficiency are evident in Figure 35 for the splashing model near the wing root and on the base of the windshield. These are due to re-impingement of mass splashed from the nose.

\section{Conclusion}

The analytical and experimental comparisons for pressure distribution and collection efficiency using the NASA Glenn splashing model were in general good. The collection efficiency models in LEWICE and LEWICE3D also compared well for the 2D wing models.

The analytical pressure distributions for all but the multi-element wing compared well with experiment. Small differences were noted near the pressure peak and near the trailing edges for most of 
the models. These differences were attributable to deficiencies in the inviscid flow-fields and to grid resolution. The multi-element wing results proved less then satisfying. The inclusion of viscous effects, wind tunnel walls and AOA adjustments did not produce excellent agreement to experimental data. The pressure distributions on the slat proved to be the worst while those on the main element and tail were reasonable. These differences were enough to cast doubt on the collection efficiency results obtained using these flow-fields. It was concluded that more work is require to produce a better multi-element flow-field.

The SLD splashing model generated good agreement with the experimental collection efficiency data for all but the multi-element wing. The differences in overall collection efficiency between experiment and the analytical splashing model were on the order of about 5 percent for all models except the multielement which was on the order of about 30 percent. The large difference for the multi-element case was attributed to flow-field errors. The splashing model fared much better than the standard, non-splashing model for which the total collection efficiency differences were as high as 30 percent.

The collection efficiency results for the trap wing and DLR-F4 cases were similar to those for the IRT test models. The splashing models resulted in a mass loss of about 15 to 30 percent. Some of the splashed mass for the cases re-impinged on downstream components. The re-impingement though was in general small for these cases and was less than 5 percent of the impinging mass.

\section{References}

1. Bond, T., Potapczuk, M., and Miller, D., “Overview of SLD Engineering Tool Development,” AIAA -2003-386, Jan. 2003.

2. Federal Aviation Regulation, Part 25, “Airworthiness Standard: Transport Category Airplanes, Appendix C,” DOT, FAA, 1974, rev. 1982.

3. Wright, W.B., "Users Manual for the NASA Glenn Ice Accretion Code LEWICE Version 3.0," available on the NASA LEWICE 3.0 release CD, Apr. 2003.

4. Bidwell, C.S., and Potapczuk, M.G., "Users Manual for the NASA Lewis Three-Dimensional Ice Accretion Code (LEWICE3D),” NASA TM-105974, Dec. 1993.

5. Papadakis, M., Elangonan, G., Fruend, G., Breer, M., and Whitmer, L., “An Experimental Method for Measuring Water Droplet Impingement Efficiency on Two-and Three-Dimensional Bodies,” NASA CR 4257, DOT/ FAA/CT-87/22, Nov. 1989.

6. McGhee, R.J., Beasley, W.D., "Low-Speed Aerodynamic Characteristics of a 17-Percent-Thick Medium-Speed Airfoil Designed for General Aviation Application,” NASA TP-1786, 1980.

7. McGhee, R.J., Viken, J.K., Pfenninger, W., Beasley, W.D. and Harvey, W.D., "Experimental Results for a Flapped Natural-Laminar-Flow Airfoil,” NASA TM-85788, 1984.

8. Shin, J., Wilcox, P., Chin, V., Sheldon, D., "Icing Test Results on an Advanced Two-Dimensional High-Lift Multi-Element Airfoil,” NASA TM-106620, AIAA-94-1869, Jun. 1994.

9. Johnson, P., Jones, K. M., and Madson, M., "Experimental Investigation of a Simplified 3D High Lift Configuration in Support of CFD Validation,” AIAA- 2000-4217, Aug. 2000.

10. Redeker, G.,” A Selection of Experimental Test Cases for the Validation of CFD Codes, Volume II," AGARD Advisory Report 303, August 2004.

11. Soedher, R.H., Andracchio, C.R., "NASA Lewis Icing Research Center Tunnel User Manual,” NASA TM-82790, 1990.

12. S. Chakravarthy, U. Goldberg, O. Peroomian and B. Sekar, "Some Algorithmic Issues in Viscous Flows Explored using a Unified-Grid CFD Methodology,” 13th AIAA CFD Conference, Snowmass, June 1997.

13. S. Chakravarthy, O. Peroomian and B. Sekar, "Some Internal Flow Applications of a Unified-Grid CFD Methodology,” AIAA-96-2024, FL, 1996.

14. Ashby, D., Dudley, M., Iguchi, S., "Development and Validation of an Advanced Low-Order Panel Method,” NASA TM-101024, Oct. 1988. 
15. Frink, N.T., Pirzadeh, S.Z, Parikh, P.C., Pandya, M.J., and Bhat, M.K., “The NASA Tetrahedral Unstructured Software System ,” The Aeronautical Journal, Vol. 104, No. 1040, Oct. 2000, pp. 491-499.

16. Mavriplis, D. J., "A Three-Dimensional Multigrid Reynolds Averaged Navier-Stokes Solver for Unstructured Meshes,” AIAA-94-1878, Jun. 1994.

17. Rogers, S. E., Kwak, D., and Kiris, C., "Numerical Solution of the Incompressible Navier-Stokes Equations for Steady-State and Time-Dependent Problems, AIAA-89-0463, Jan. 1989.

18. Samareh-Abolhassani, J., “GridTool: A Surface Modeling and Grid Generation Tool,” Proceedings of the Workshop on Surface Modeling, Grid Generation and Related Issues in CFD Solutions, NASA CP-3291, May 1995.

19. Kania, L. and Pirzadeh, S.Z., “A Geometrically-Derived Background Function for Unstructured Mesh Generation,” AIAA-2005-5240, Jun. 2005.

20. Bidwell, C.S., "Collection Efficiency and Ice Accretion Calculations for a Boeing 737-300 Inlet," SAE Paper 91-0442, presented at the $1^{\text {st }}$ SAE-AIAA World Aviation Congress, Los Angeles, CA, Nov. 22-25, 1996.

21. Marcum, D., "Unstructured Grid Generation Using Automatic Point Insertion and Local Reconnection,” Handbook of Grid Generation, Thompson, J. F., Soni, B. K., Weatherill, N., eds., CRC Press, Boca Raton, FL, 1998.

22. Wright, W.B., "Further Refinement of the LEWICE SLD Model,” AIAA-2006-464. 
TABLE 1.-TEN BIN DISTRIBUTION FOR $92 \mu \mathrm{m}$ MVD DROP SIZE GENERATED BY

WSU SPRAY SYSTEM

\begin{tabular}{|c|c|}
\hline $\begin{array}{c}\text { Drop size } \\
(\mu \mathrm{m})\end{array}$ & $\begin{array}{c}\text { Percent } \\
\text { LWC }\end{array}$ \\
\hline 10.96046 & 0.05 \\
27.59405 & 0.1 \\
51.17964 & 0.2 \\
92.18893 & 0.3 \\
136.2497 & 0.2 \\
179.8884 & 0.1 \\
230.625 & 0.03 \\
83.3301 & 0.01 \\
339.5112 & 0.005 \\
391.7745 & 0.005 \\
\hline
\end{tabular}

TABLE 2.-TWENTY-SEVEN BIN DISTRIBUTION FOR $92 \mu \mathrm{m}$ MVD DROP SIZE GENERATED

BY WSU SPRAY SYSTEM

\begin{tabular}{|c|r|}
\hline $\begin{array}{c}\text { Drop size } \\
(\mu \mathrm{m})\end{array}$ & $\begin{array}{c}\text { Percent } \\
\text { LWC }\end{array}$ \\
\hline 10.7792 & 0.0475 \\
24.37238 & 0.0475 \\
29.77389 & 0.0475 \\
35.24709 & 0.0475 \\
41.99855 & 0.0475 \\
51.40099 & 0.0475 \\
61.50823 & 0.0475 \\
69.93255 & 0.0475 \\
77.50246 & 0.0475 \\
84.73027 & 0.0475 \\
91.71088 & 0.0475 \\
98.83237 & 0.0475 \\
106.2296 & 0.0475 \\
113.8977 & 0.0475 \\
121.8354 & 0.0475 \\
130.5719 & 0.0475 \\
140.5805 & 0.0475 \\
152.2594 & 0.0475 \\
165.6468 & 0.0475 \\
187.6024 & 0.0475 \\
209.6167 & 0.01 \\
226.1367 & 0.01 \\
247.145 & 0.01 \\
265.6669 & 0.005 \\
290.3102 & 0.005 \\
339.5112 & 0.005 \\
391.7745 & 0.005 \\
\hline
\end{tabular}




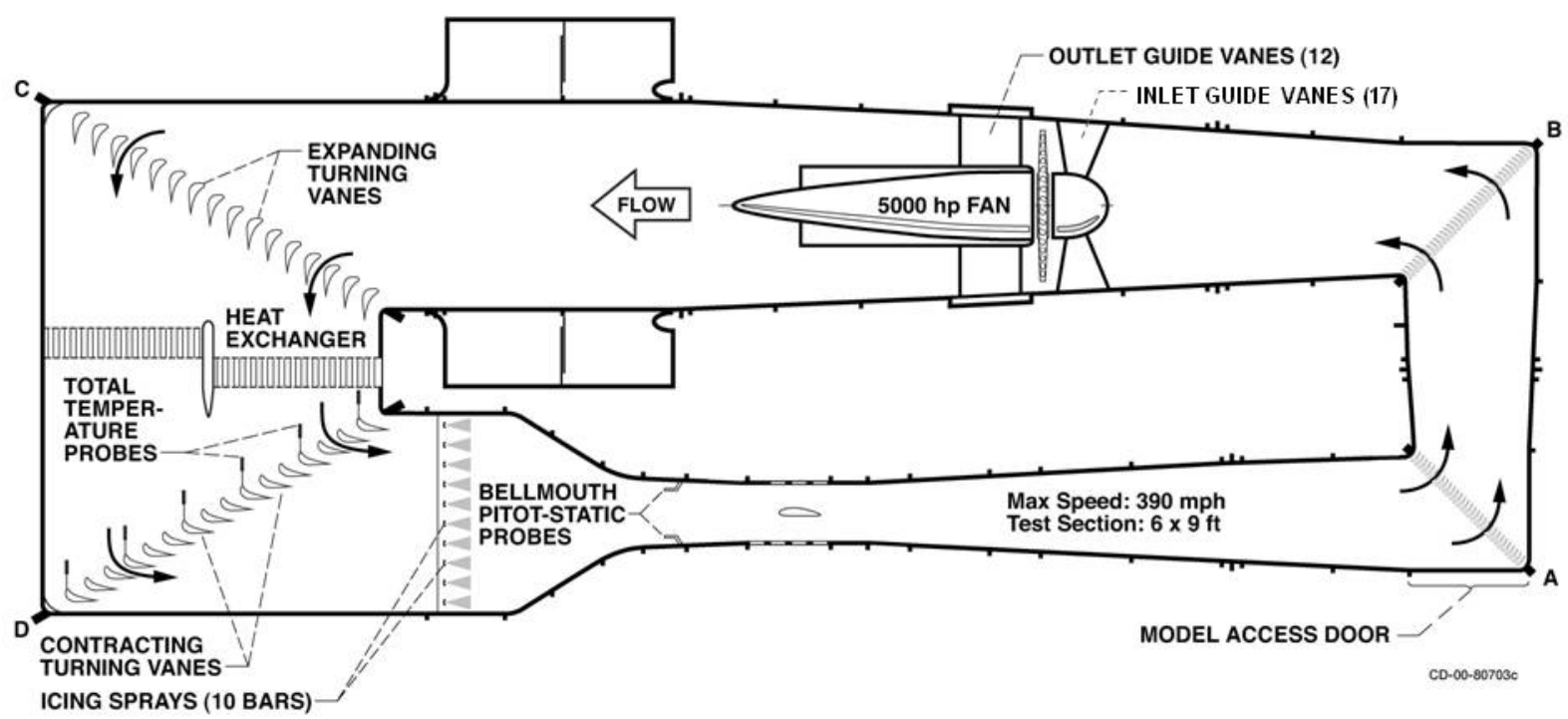

Figure 1.-NASA Glenn Icing Research Tunnel (IRT). Plan view.

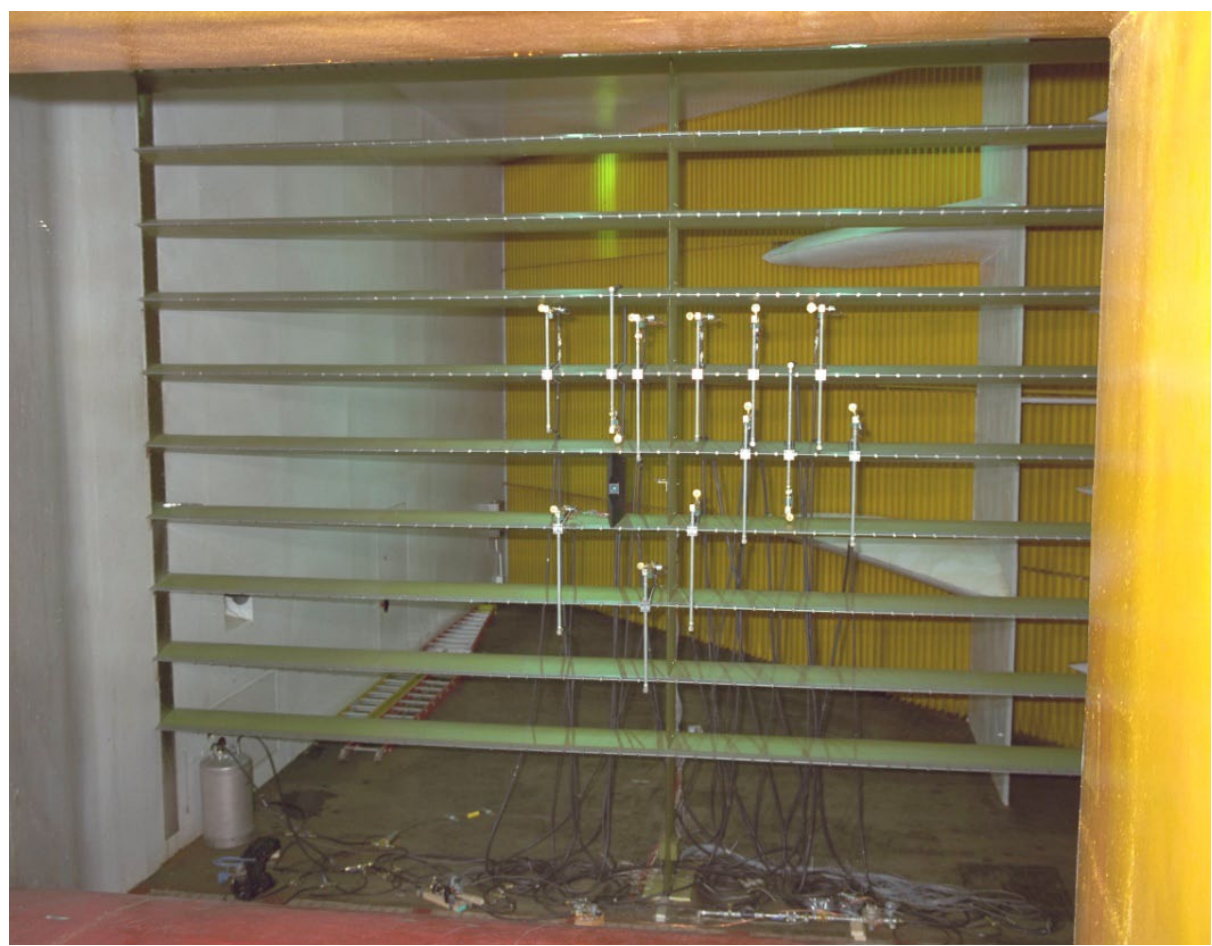

Figure 2.-Installation of spray system used for IRT impingement tests. 


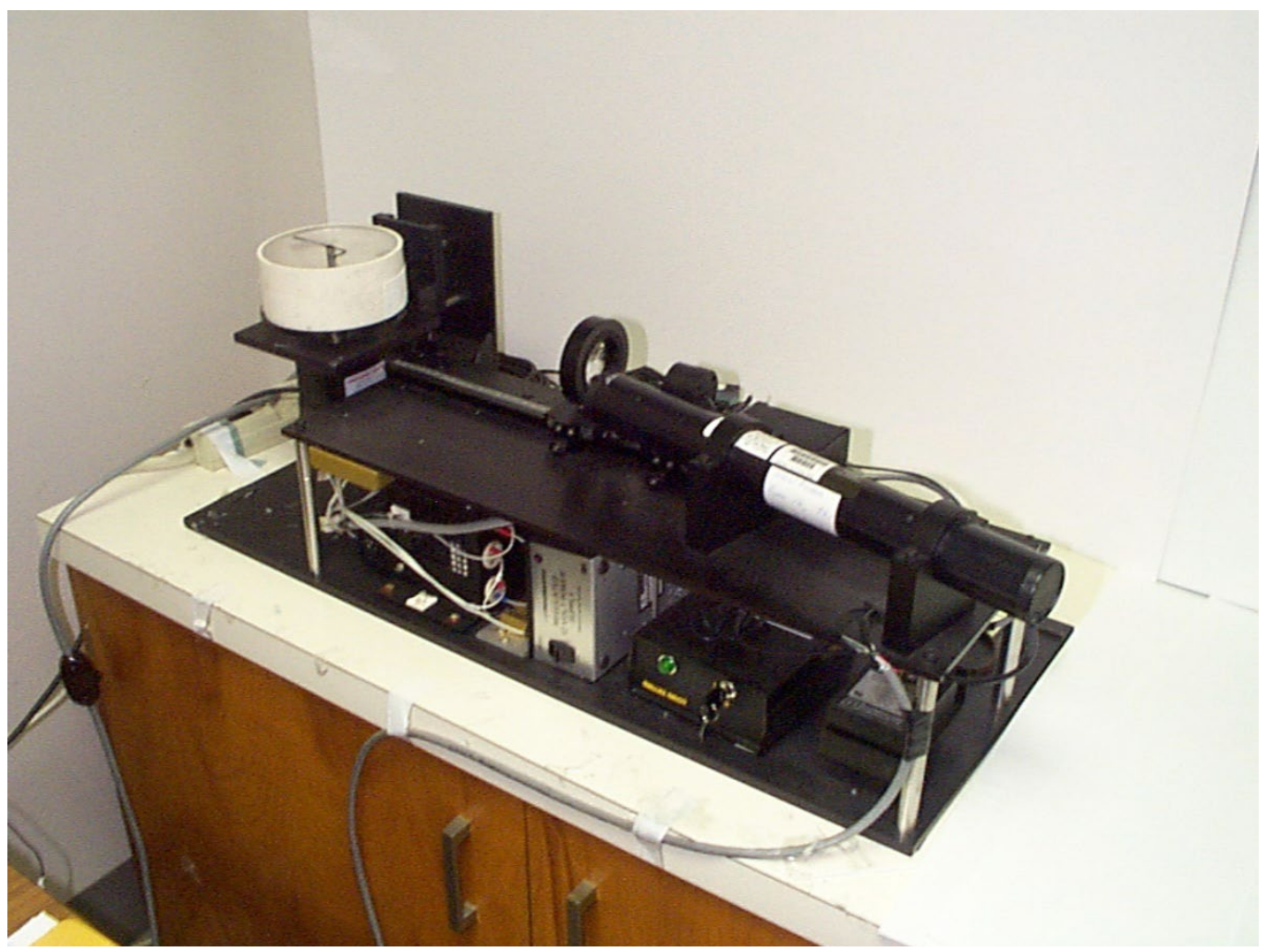

Figure 3.-Automated reflectometer used to reduce impingement data.

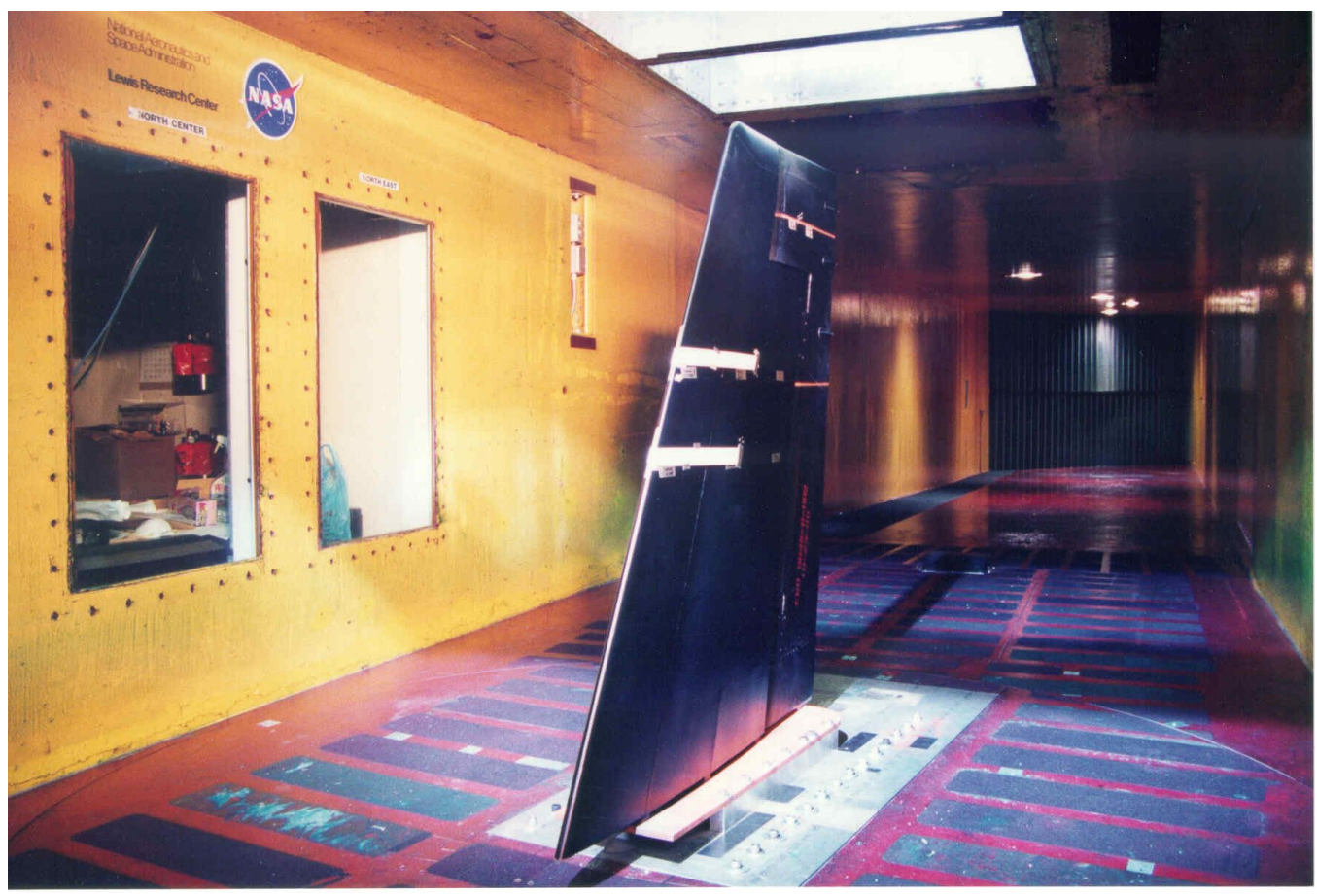

Figure 4.- - Illustration of blotter strip application. 


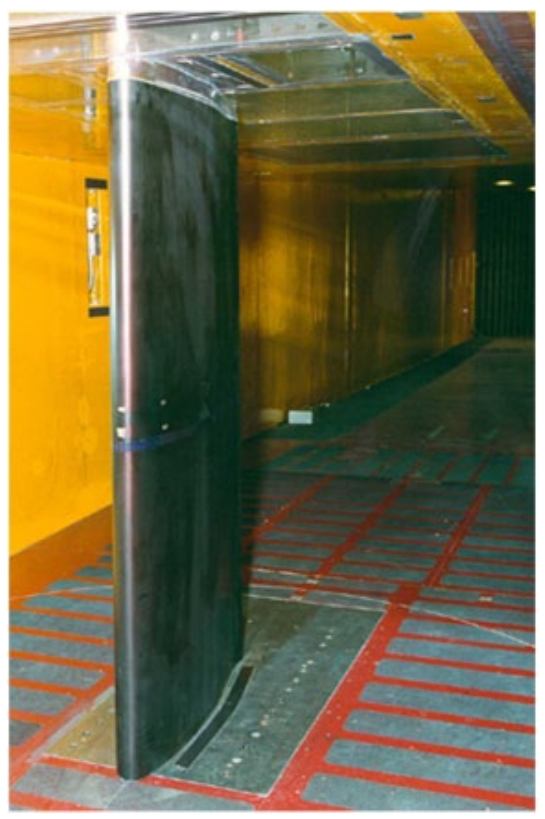

(a) IRT installation.

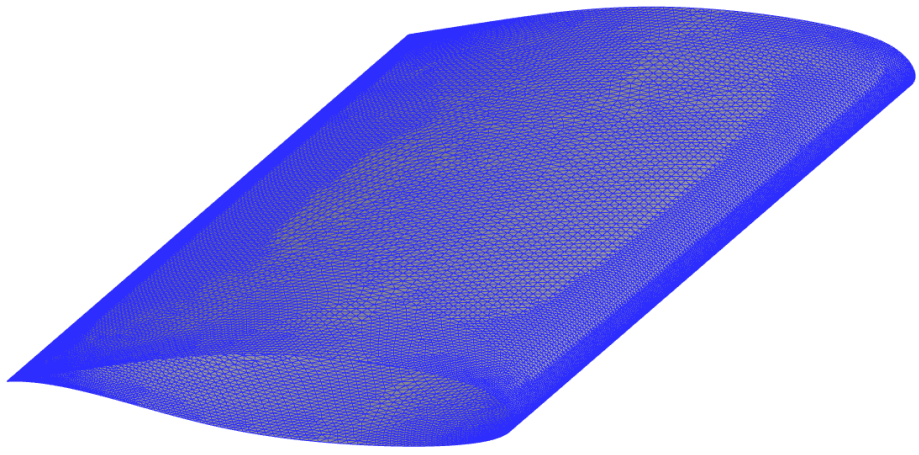

(b) USM3D surface grid.

Figure 5.-MS-317 model.
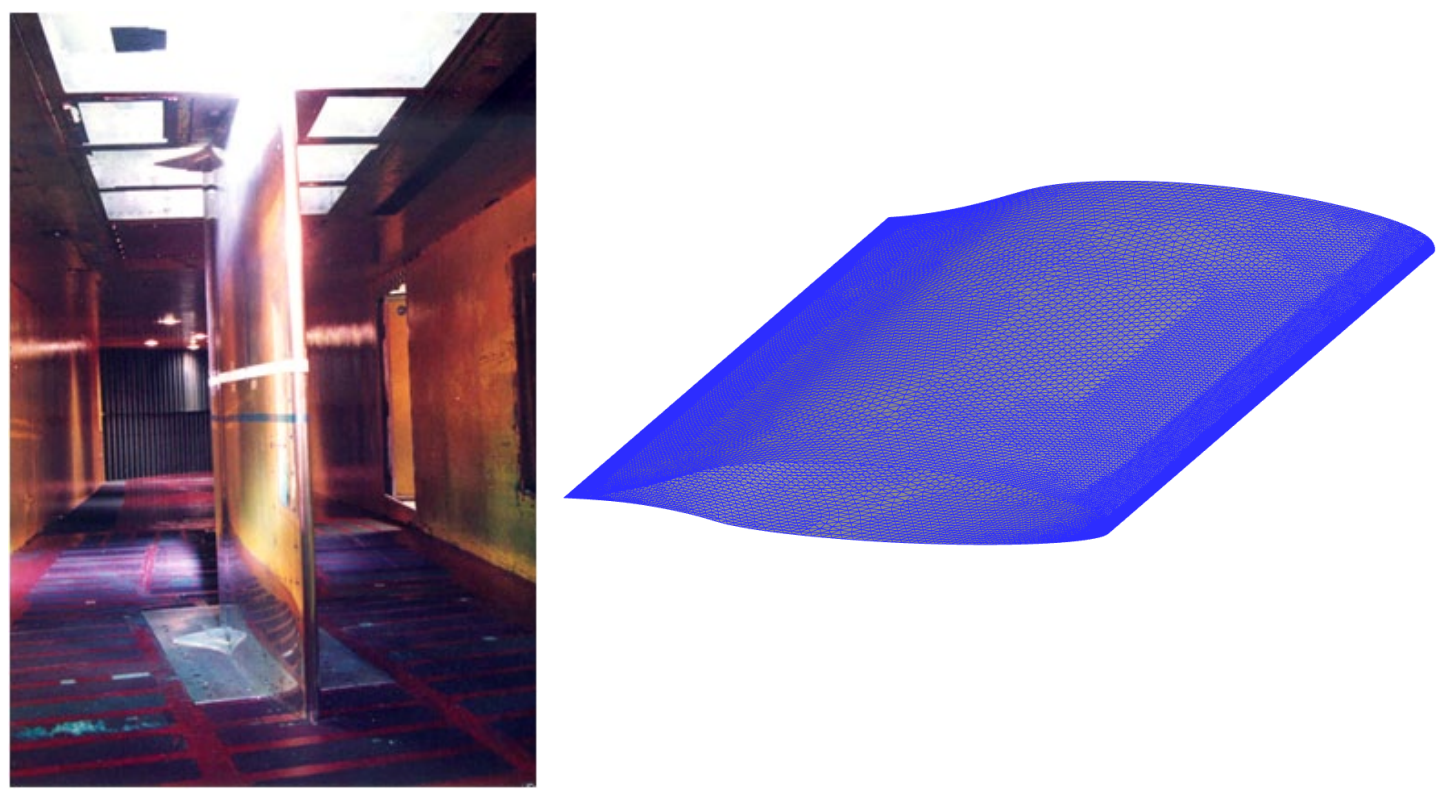

(a) IRT installation.

(b) USM3D surface grid.

Figure 6. -NLF(1)-0414 model. 


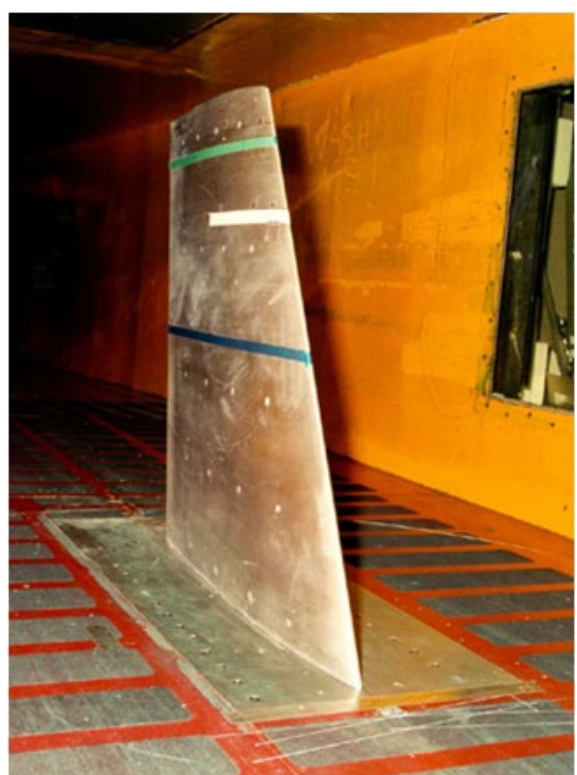

(a) IRT installation.

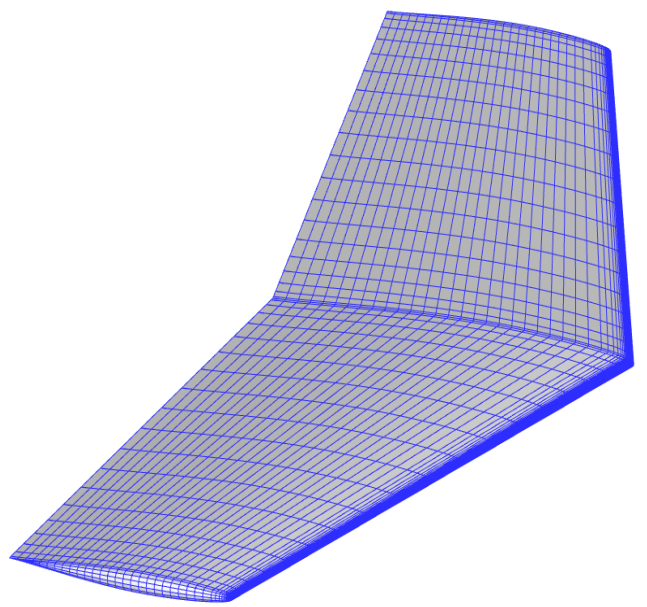

(b) PMARC surface model.

Figure 7.-Swept 64A008 wing.

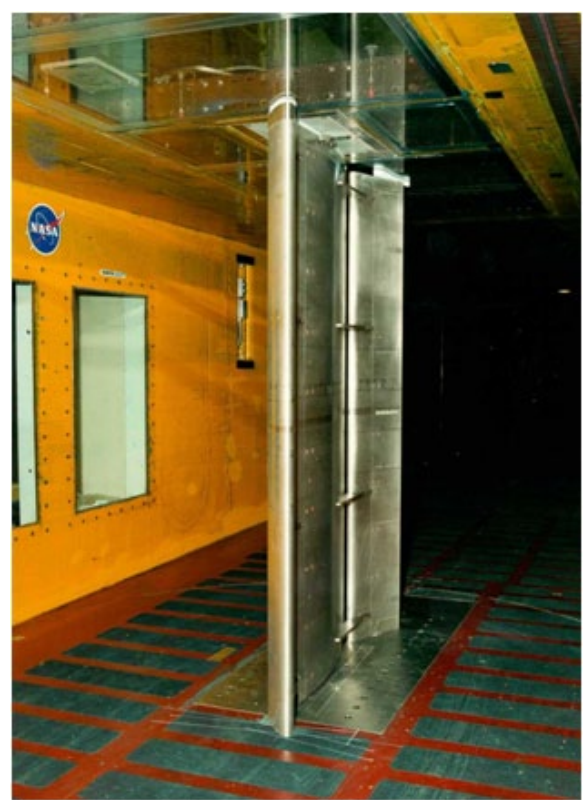

(a) IRT installation.
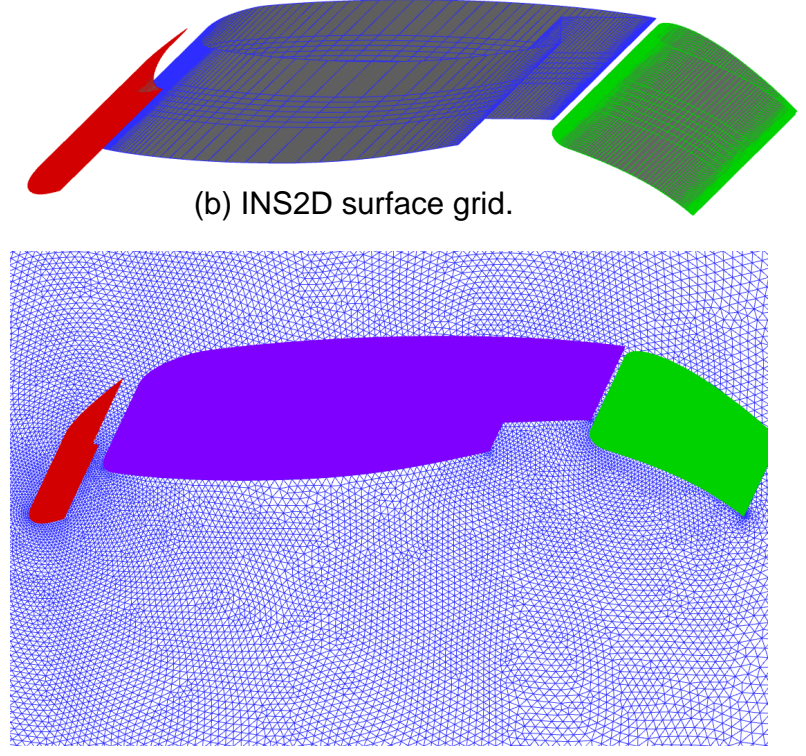

(c) USM3D surface grid.

Figure 8.-Multi-element model. 


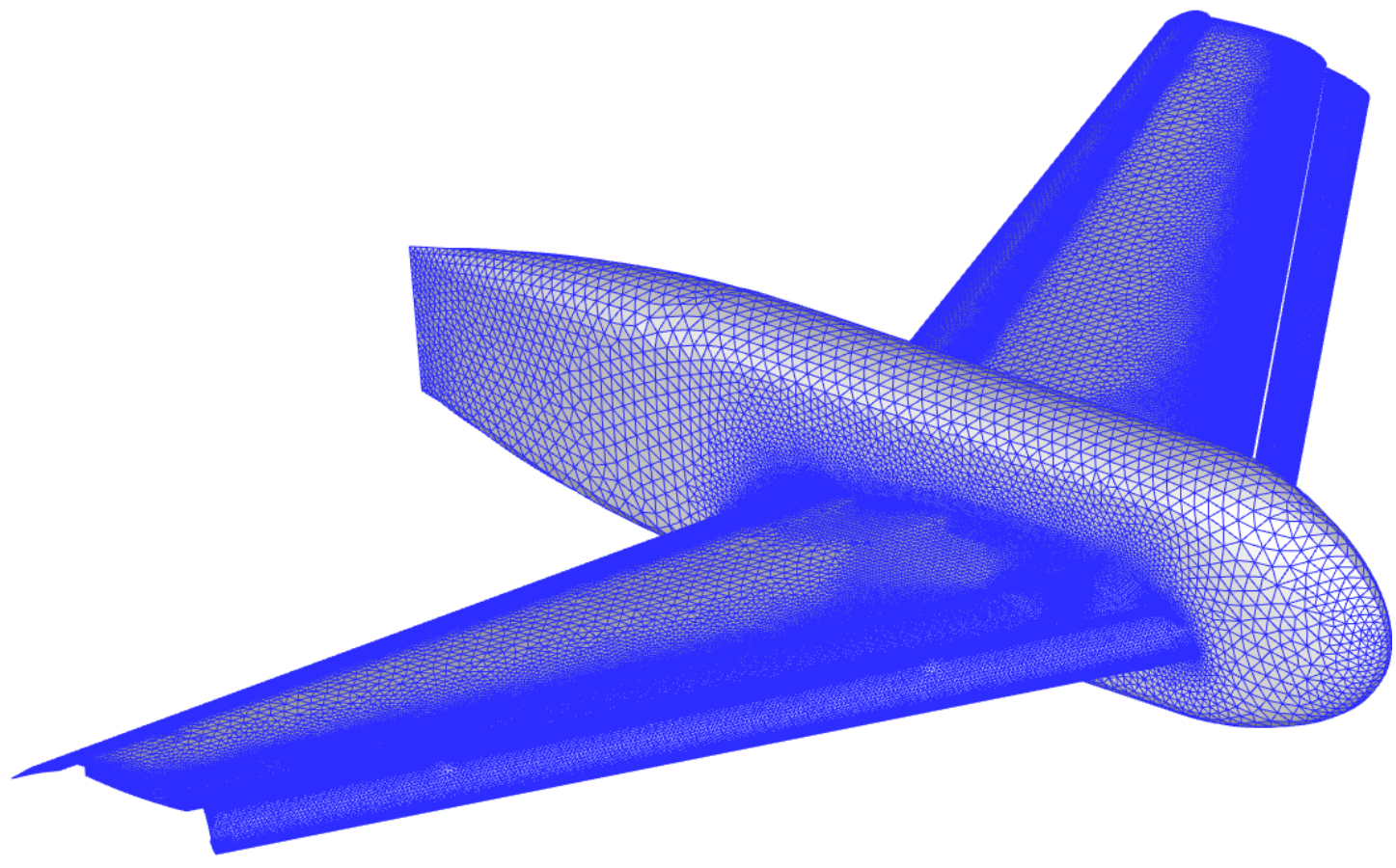

Figure 9.-Surface model for CFD++ trap wing flow model.

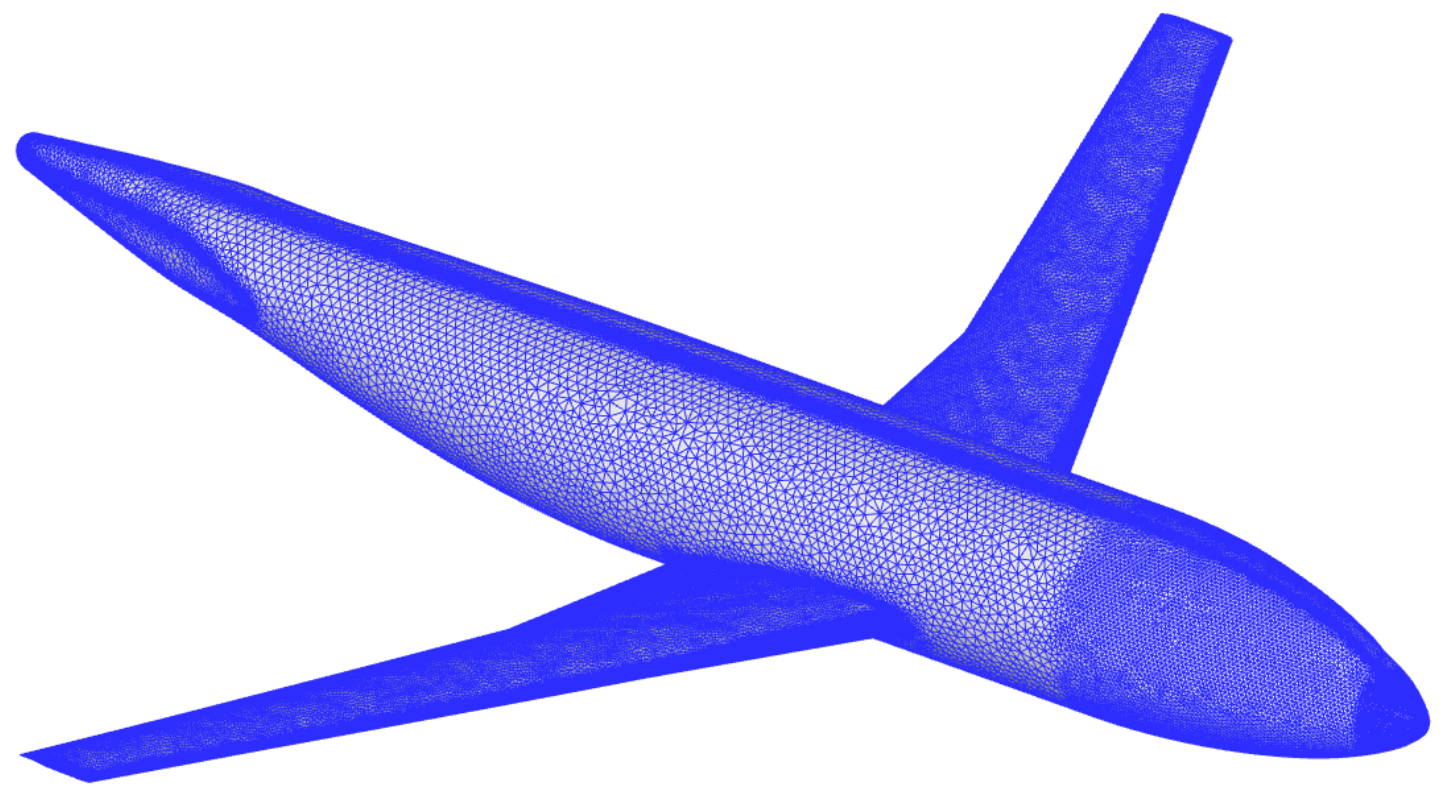

Figure 10.-Surface model for NSU3D DLR-F4 flow model. 


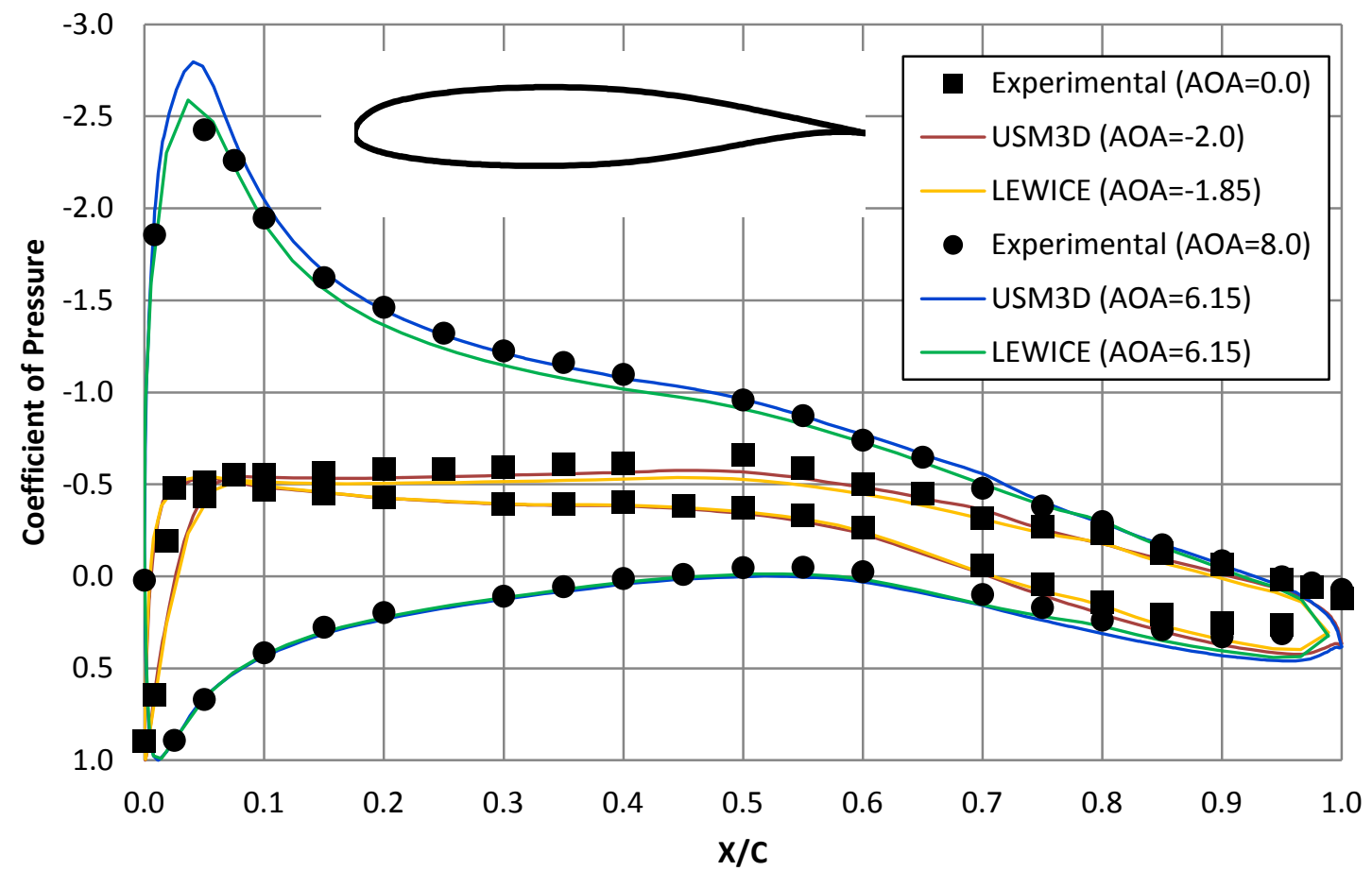

Figure 11.-Comparison of experimental and analytical coefficient of pressure distribution for MS-317 model.

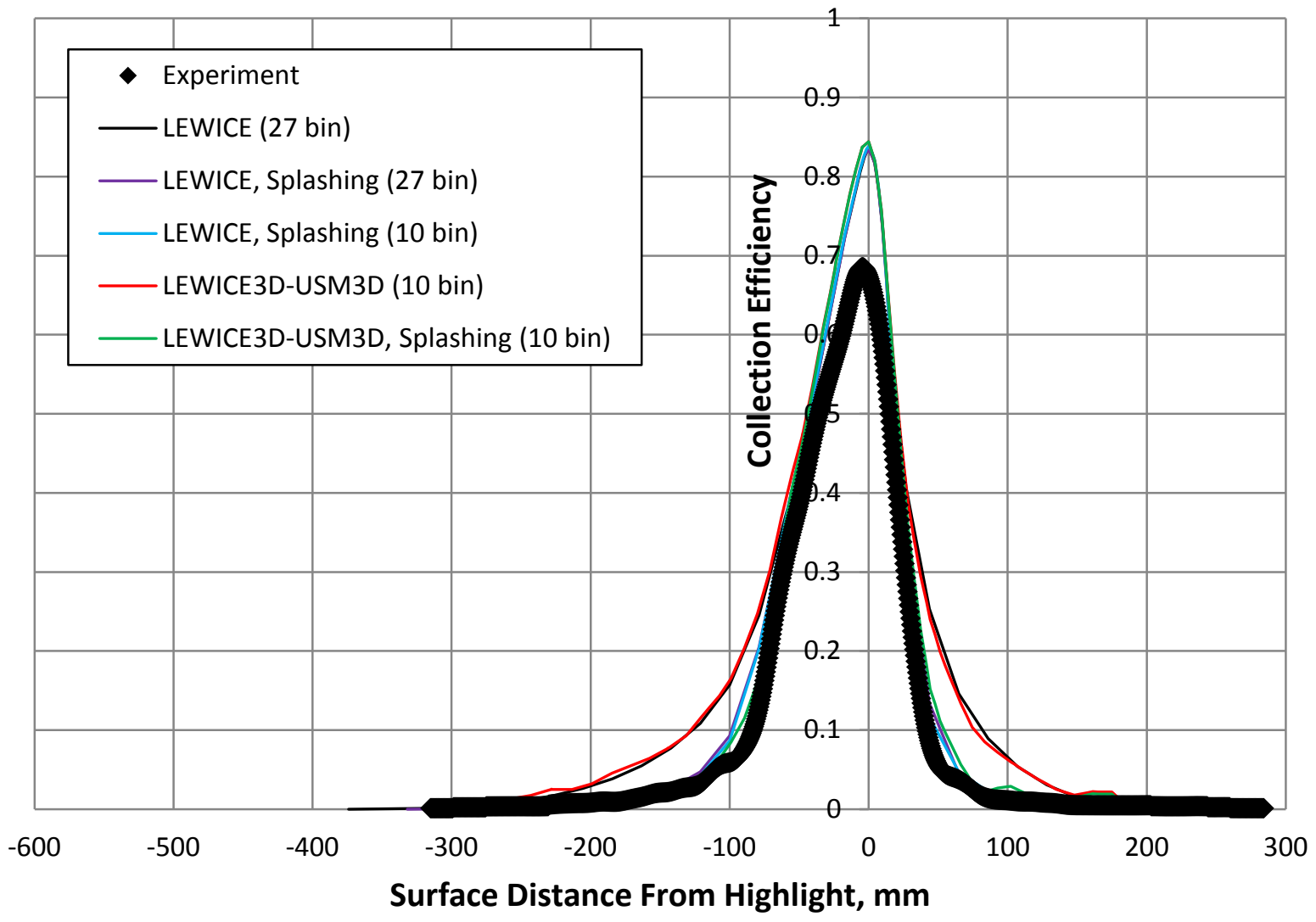

Figure 12.-Comparison of experimental and analytical collection efficiency for MS-317 model. 


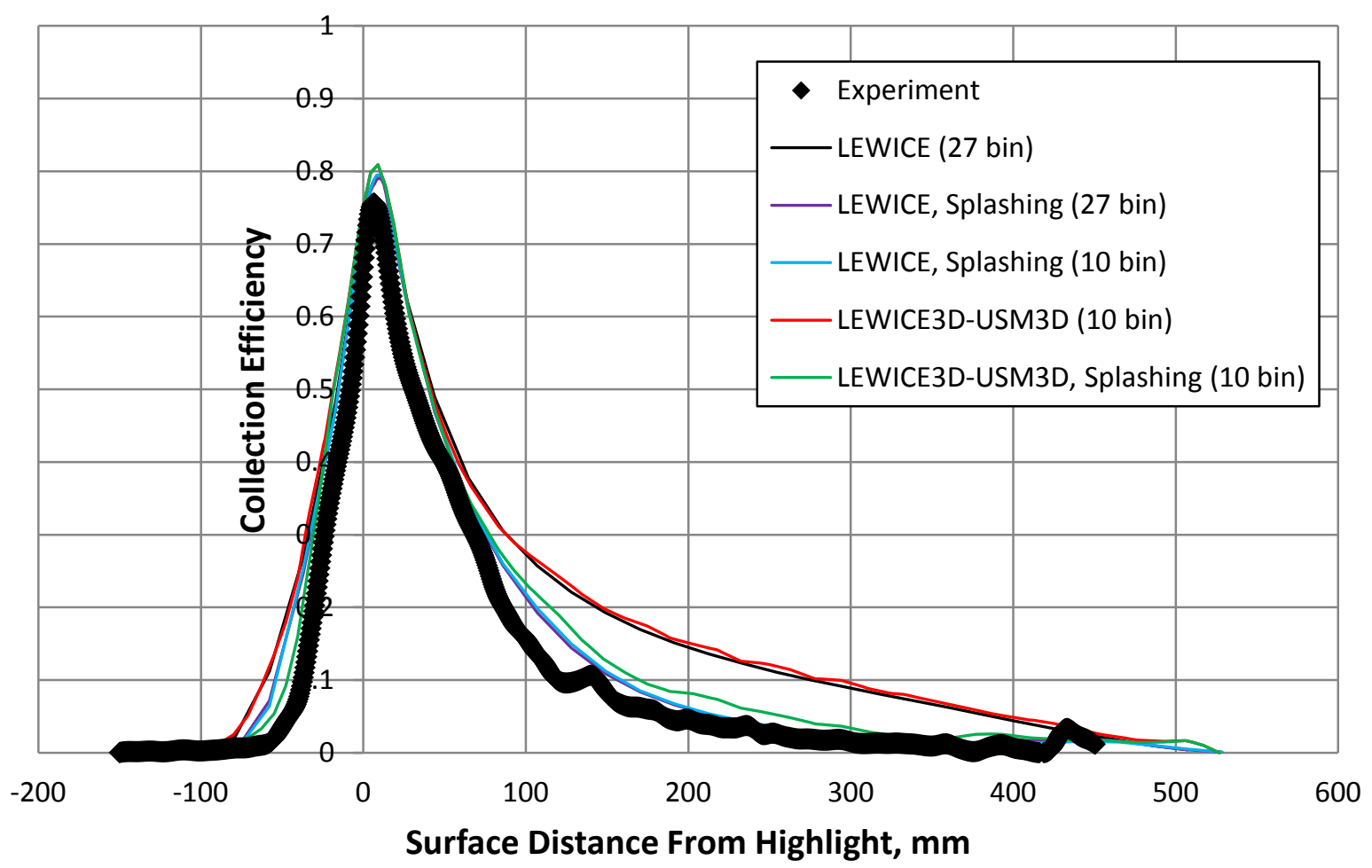

Figure 13.-Comparison of experimental and analytical collection efficiency for MS-317 model.

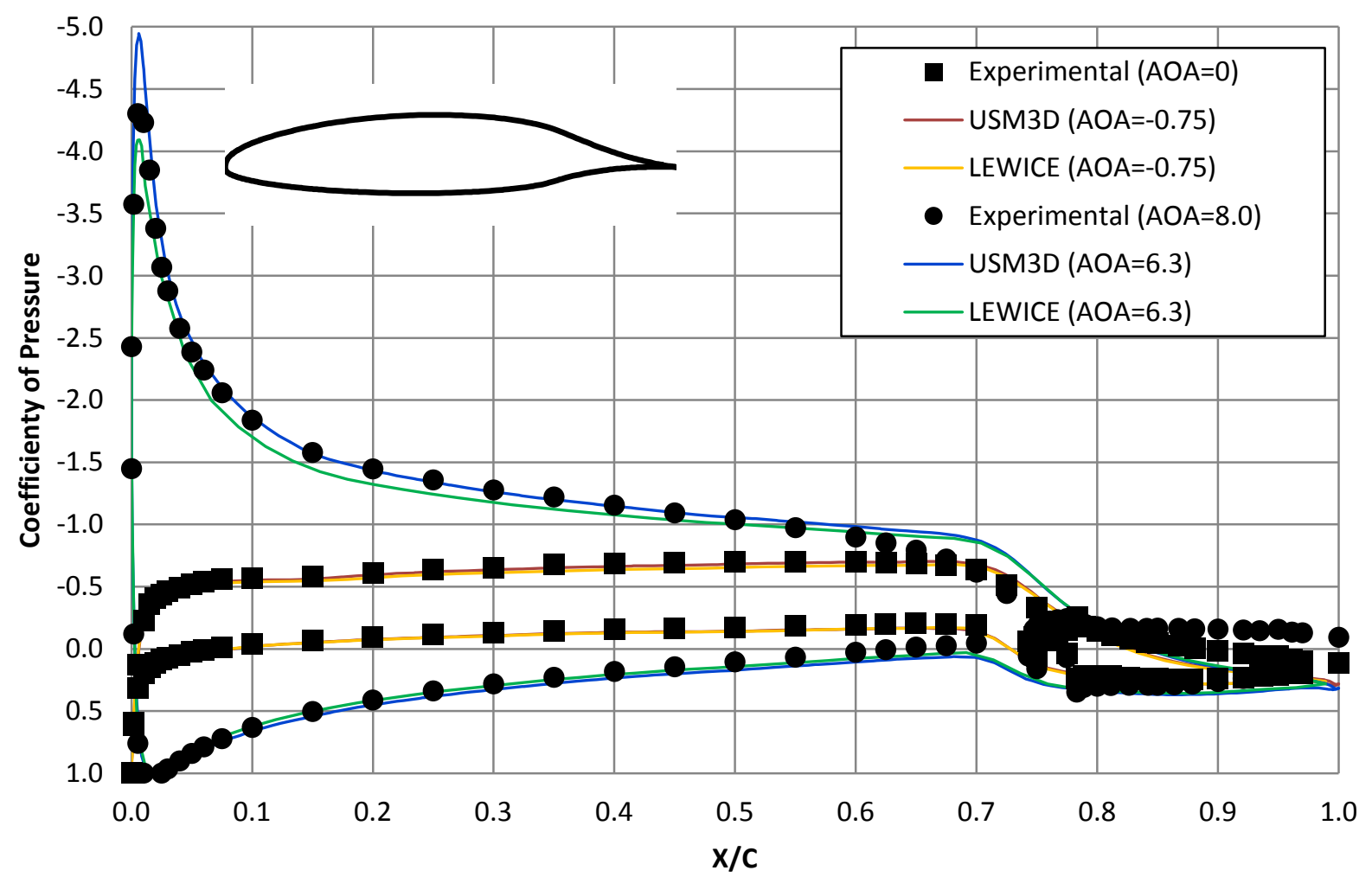

Figure 14.-Comparison of experimental and analytical coefficient of pressure distribution for NLF(1) 0414 model. 


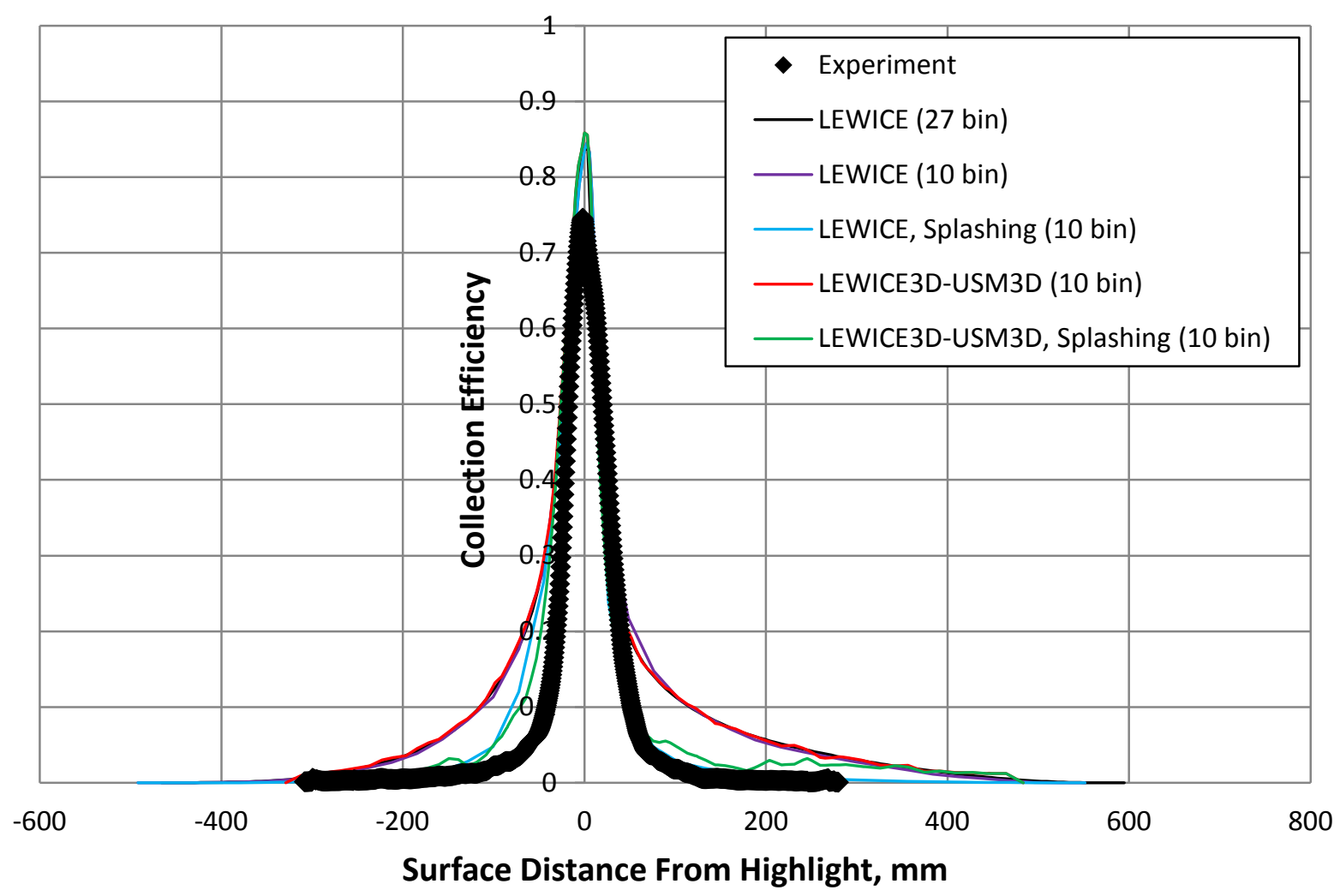

Figure 15.-Comparison of experimental and analytical collection efficiency for NLF(1) 0414 model.

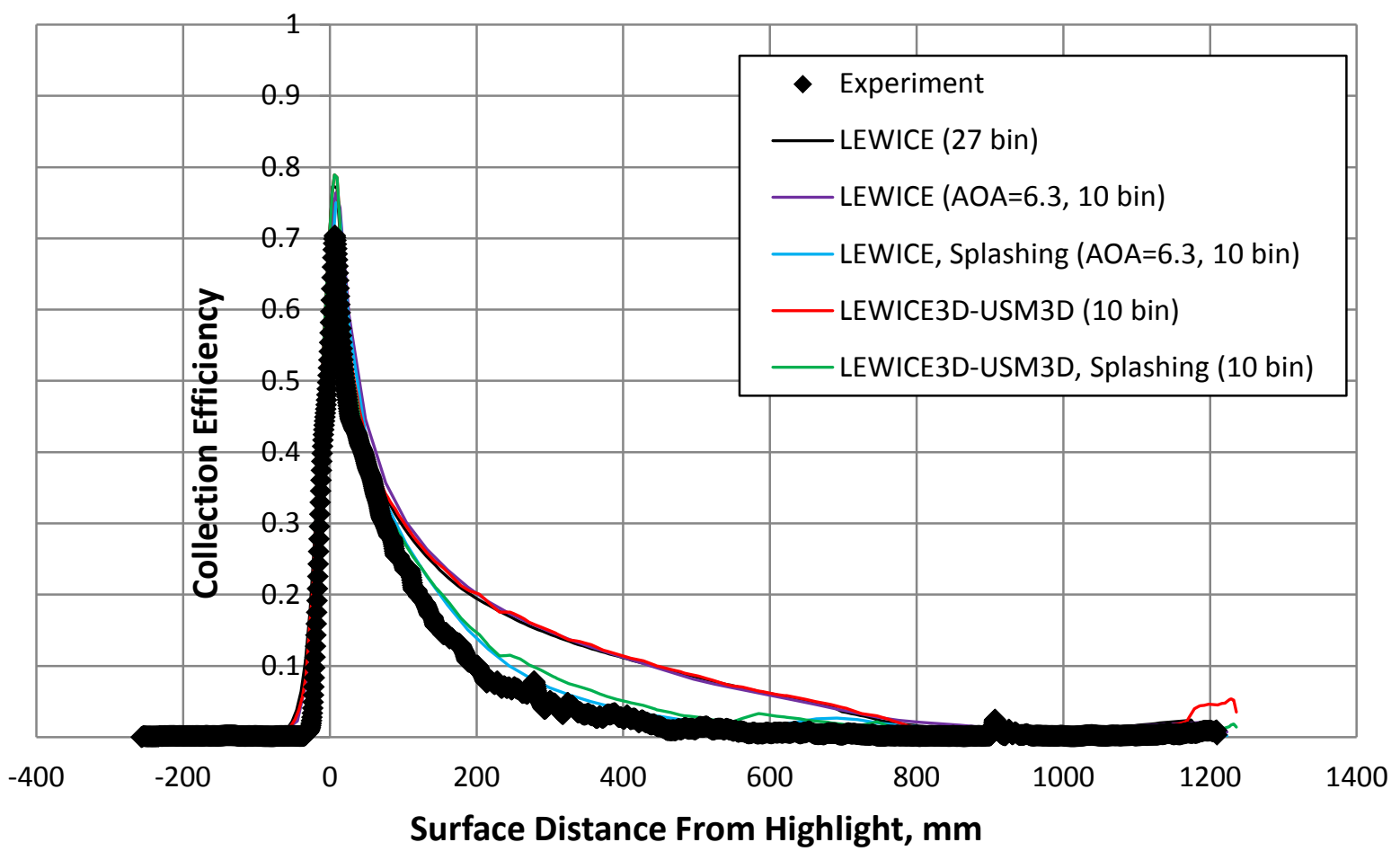

Figure 16.-Comparison of experimental and analytical collection efficiency for NLF(1) 0414 model. 


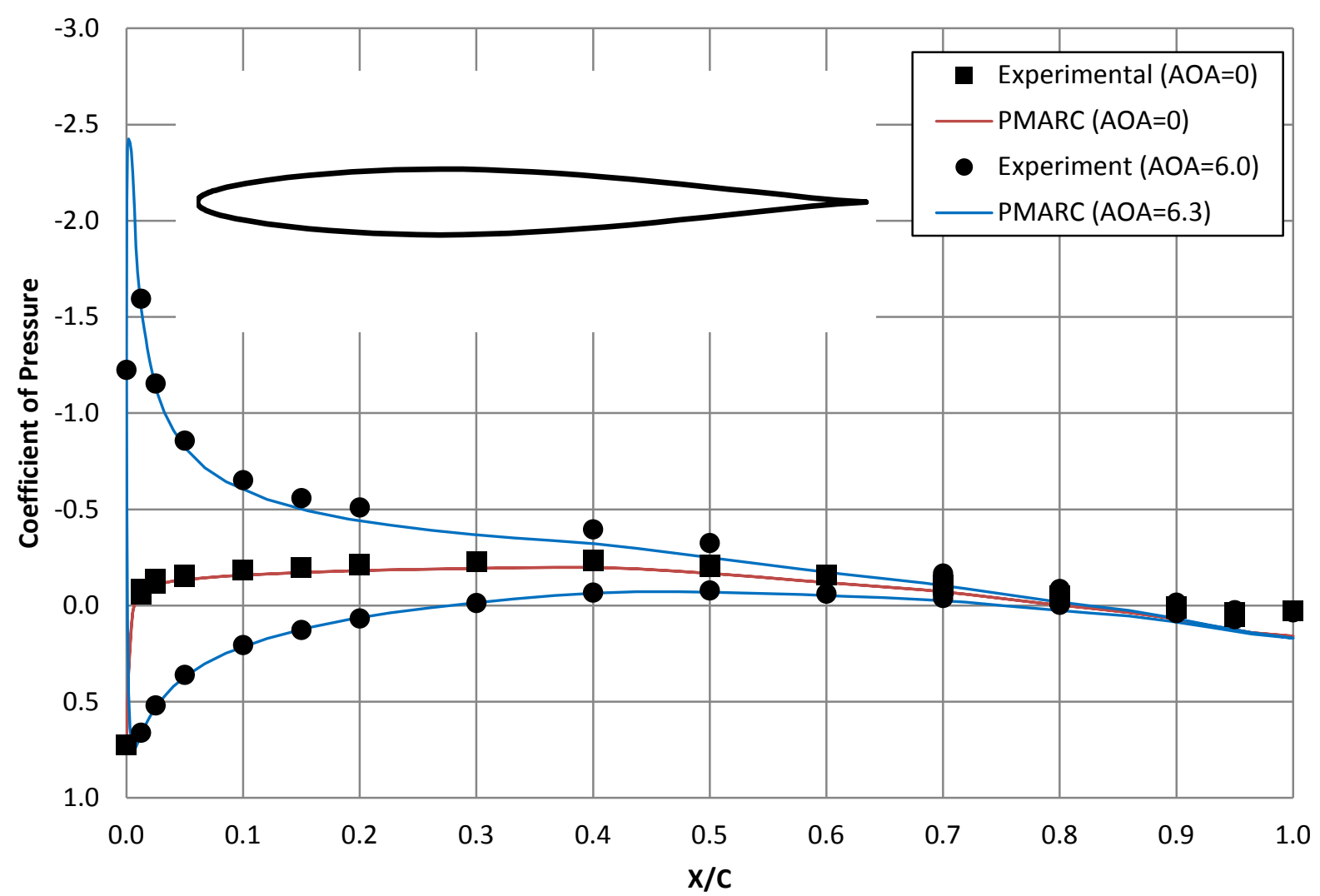

Figure 17.-Comparison of experimental and analytical coefficient of pressure for swept NACA 64A008 wing.

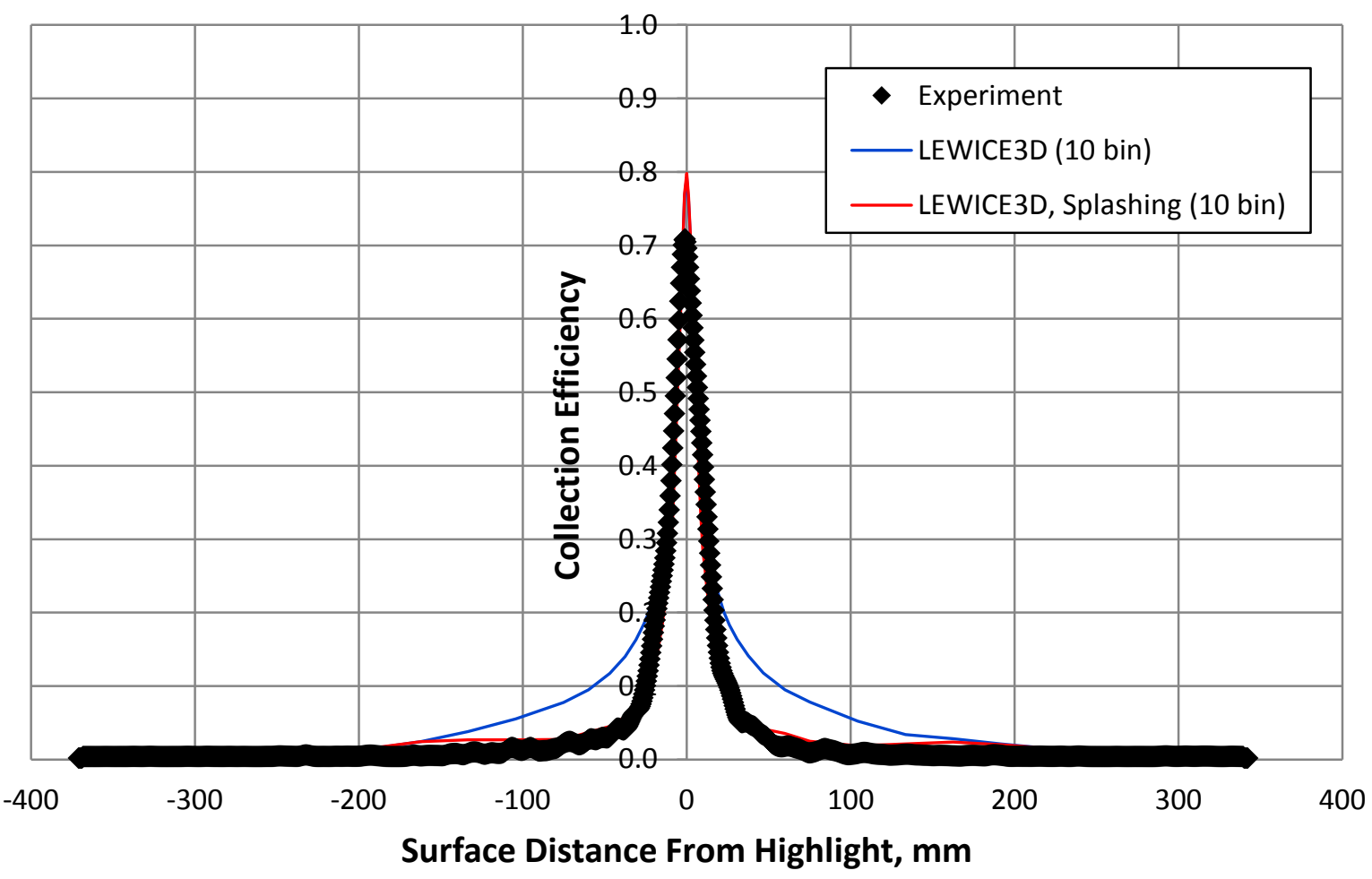

Figure 18.-Comparison of experimental and analytical collection efficiency for swept NACA 64A008 wing. 


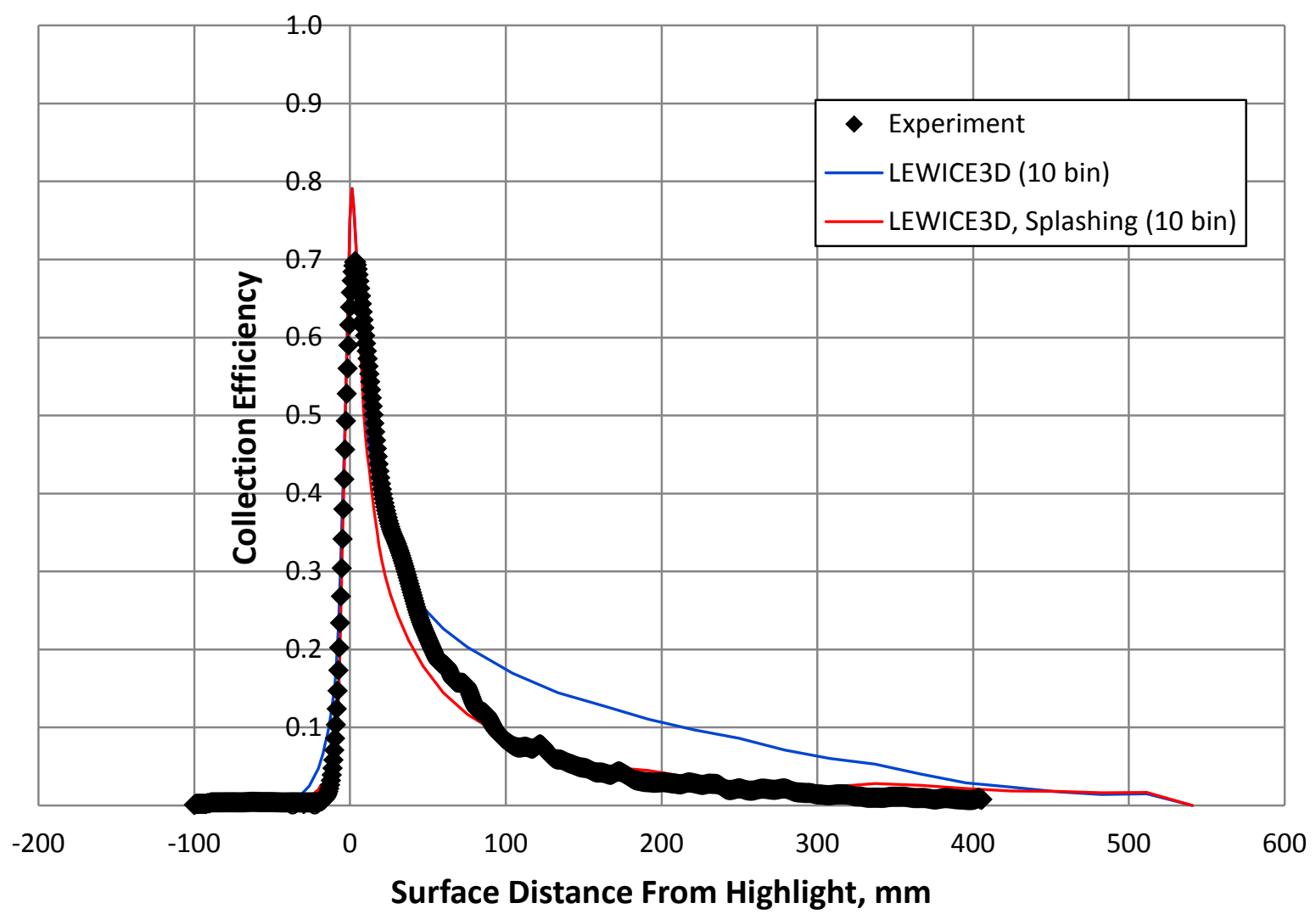

Figure 19.-Comparison of experimental and analytical collection efficiency for swept NACA 64A008 wing.

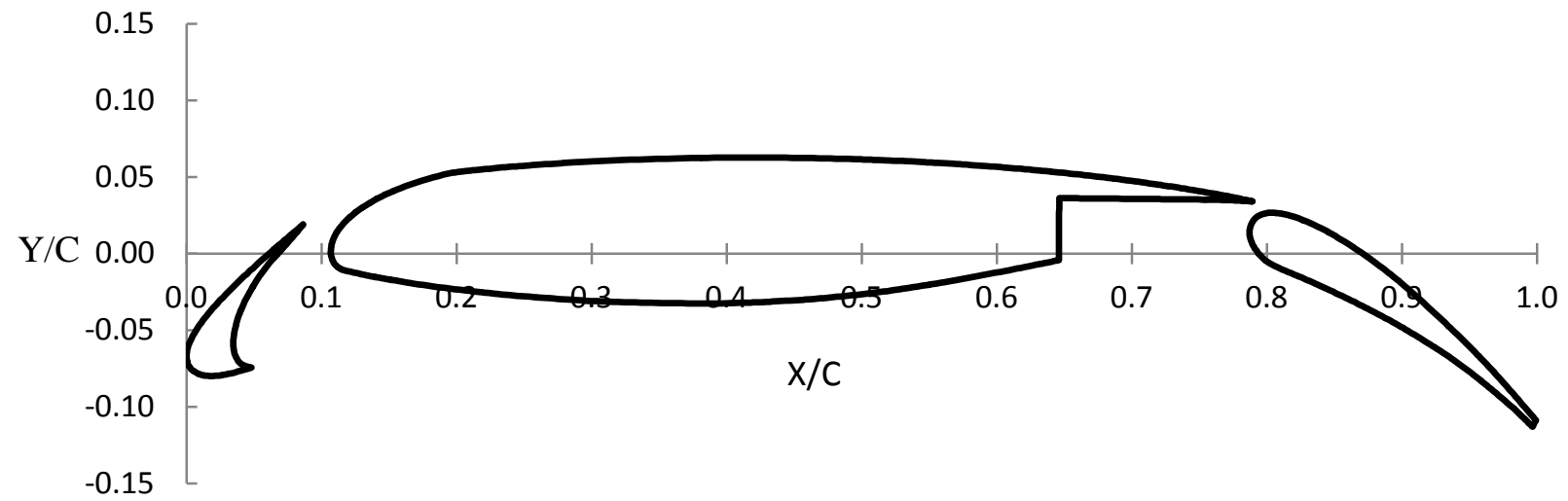

Figure 20.-Multi-element wing cross section. 


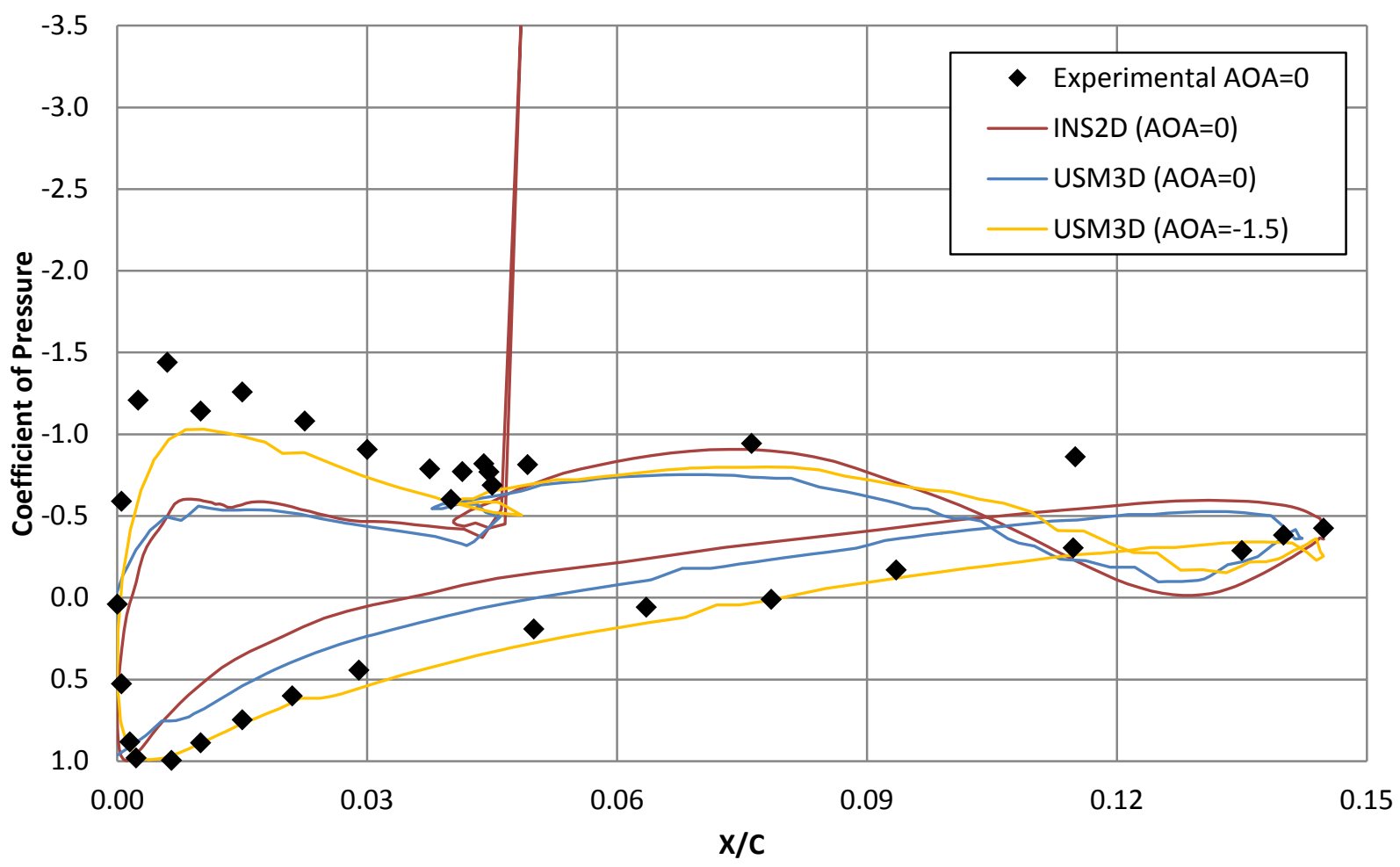

Figure 21.-Comparison of experimental and analytical pressure distribution for multi-element slat.

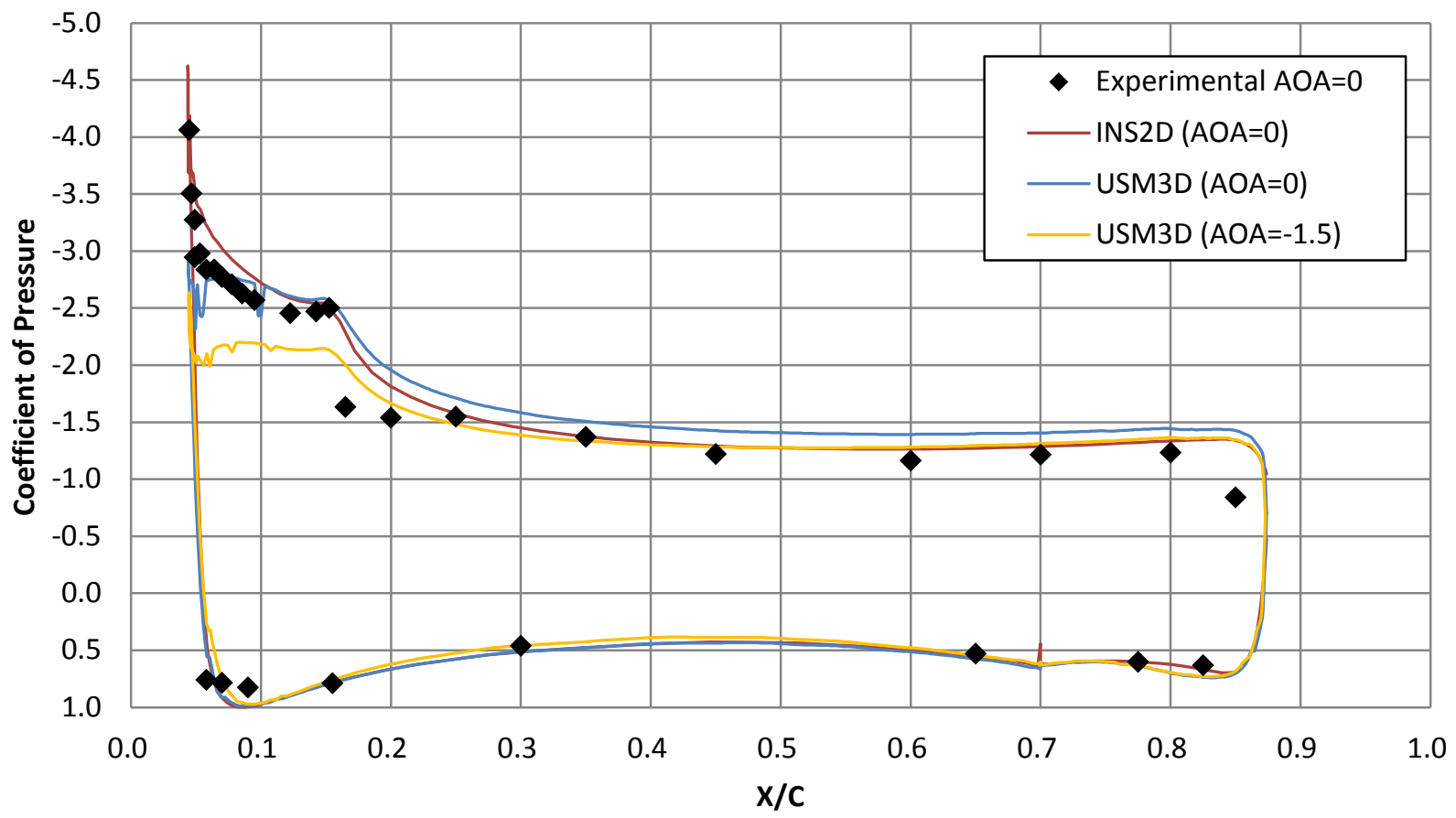

Figure 22.-Comparison of experimental and analytical pressure distribution for multi-element wing main element. 


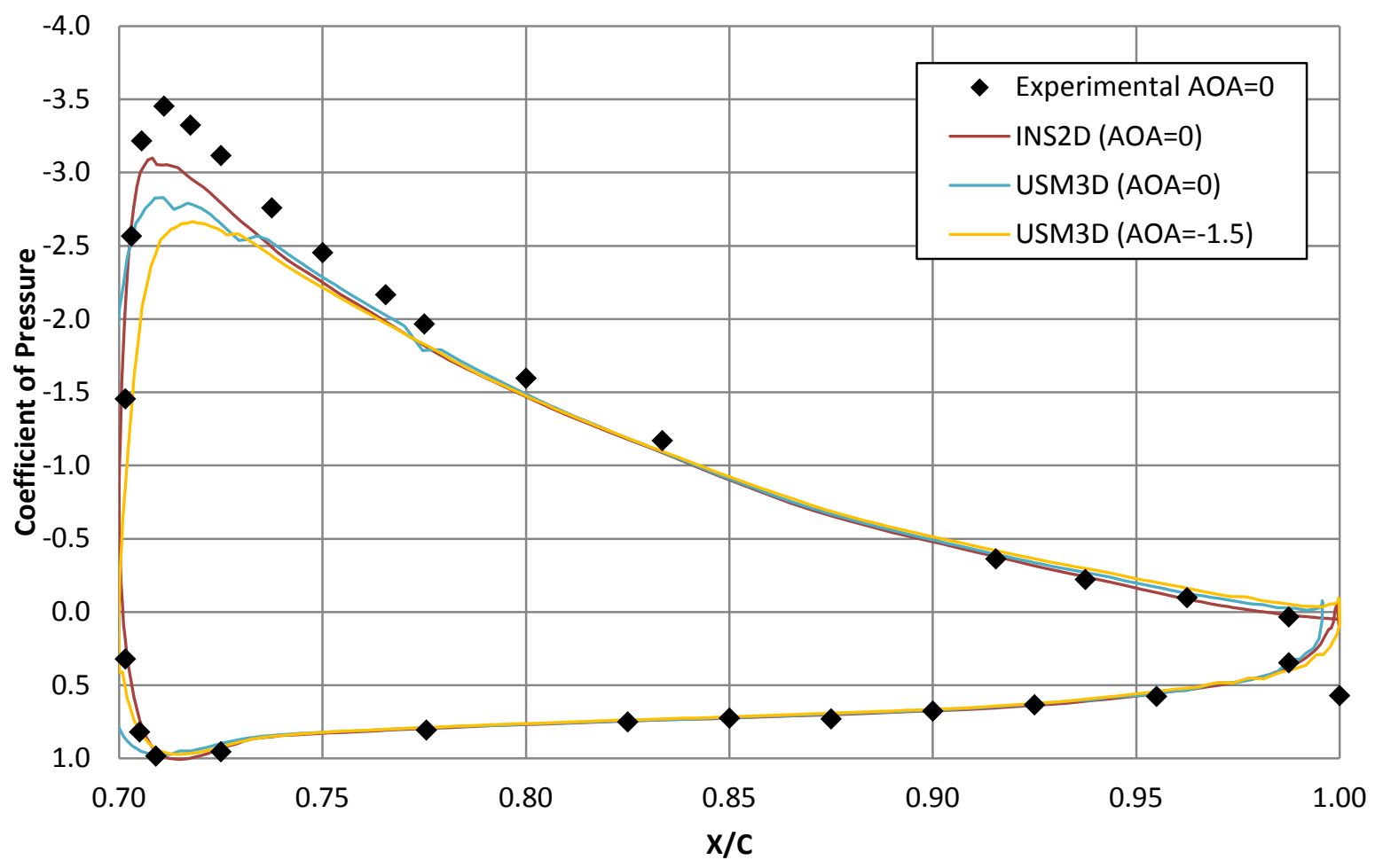

Figure 23.-Comparison of experimental and analytical pressure distribution for multi-element model flap.

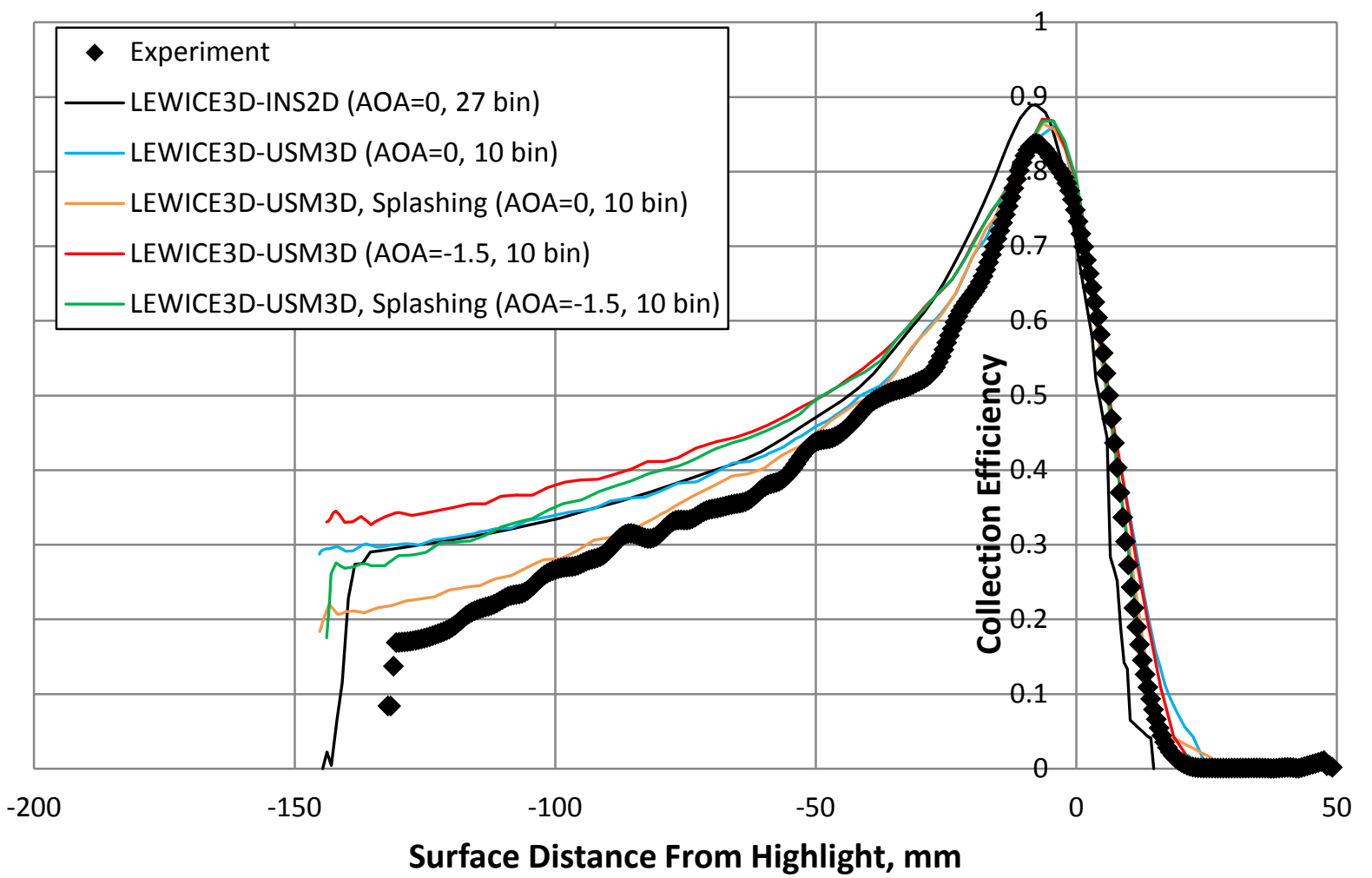

Figure 24.-Comparison of experimental and analytical collection efficiency for multi-element model slat. 


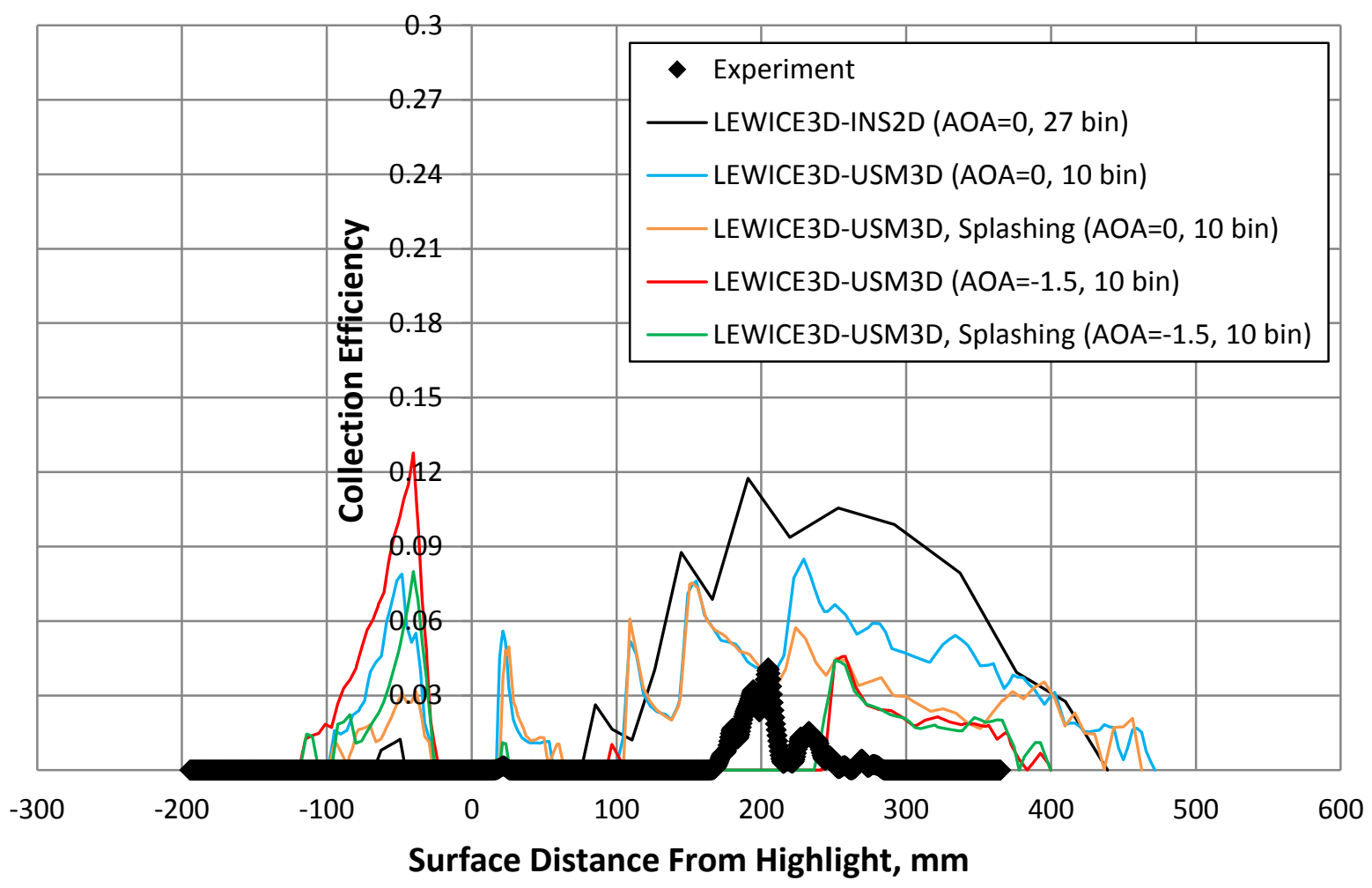

Figure 25.-Comparison of experimental and analytical collection efficiency for multi-element model main element.

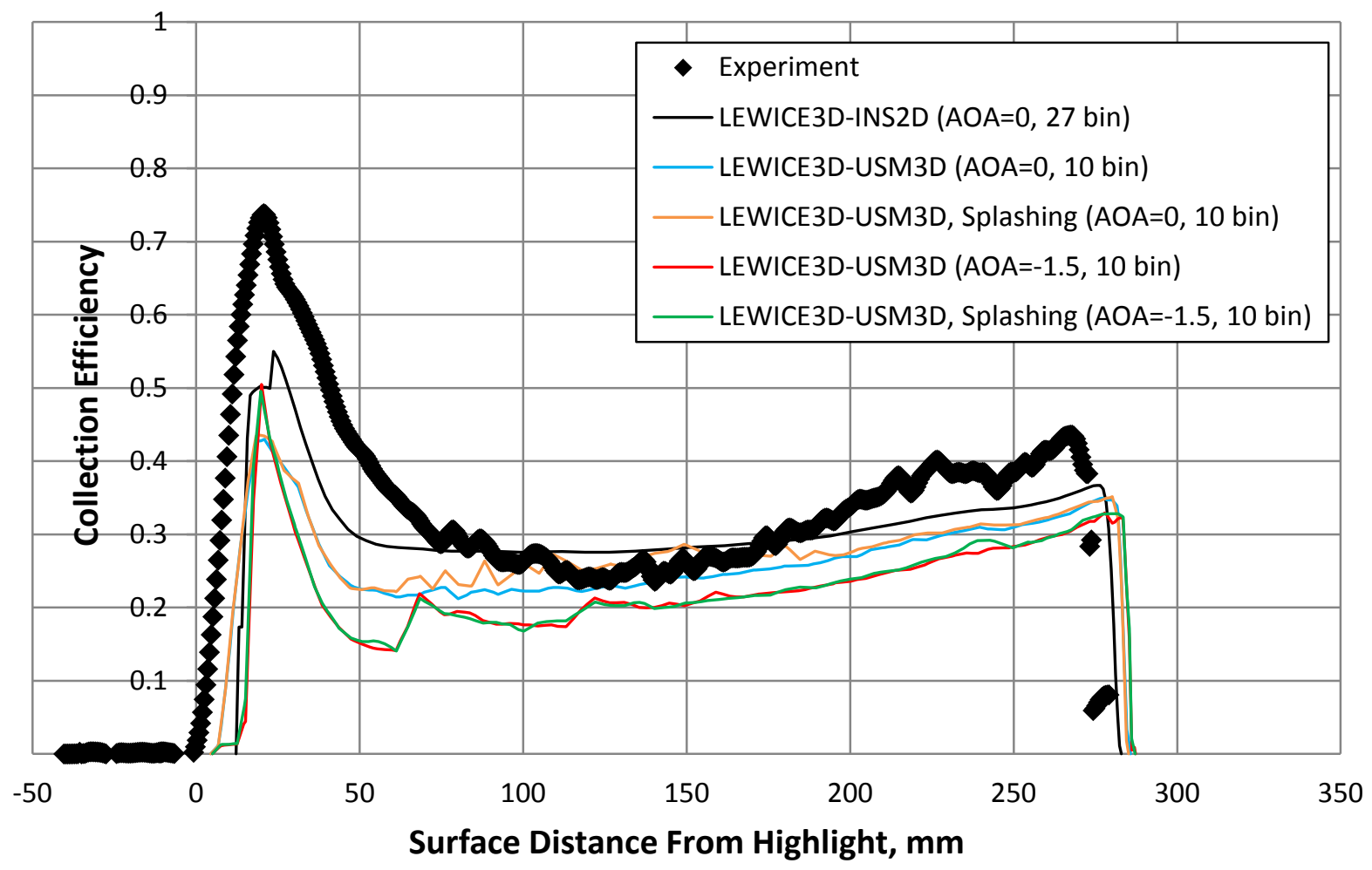

Figure 26.—Comparison of experimental and analytical collection efficiency for multi-element wing flap. 


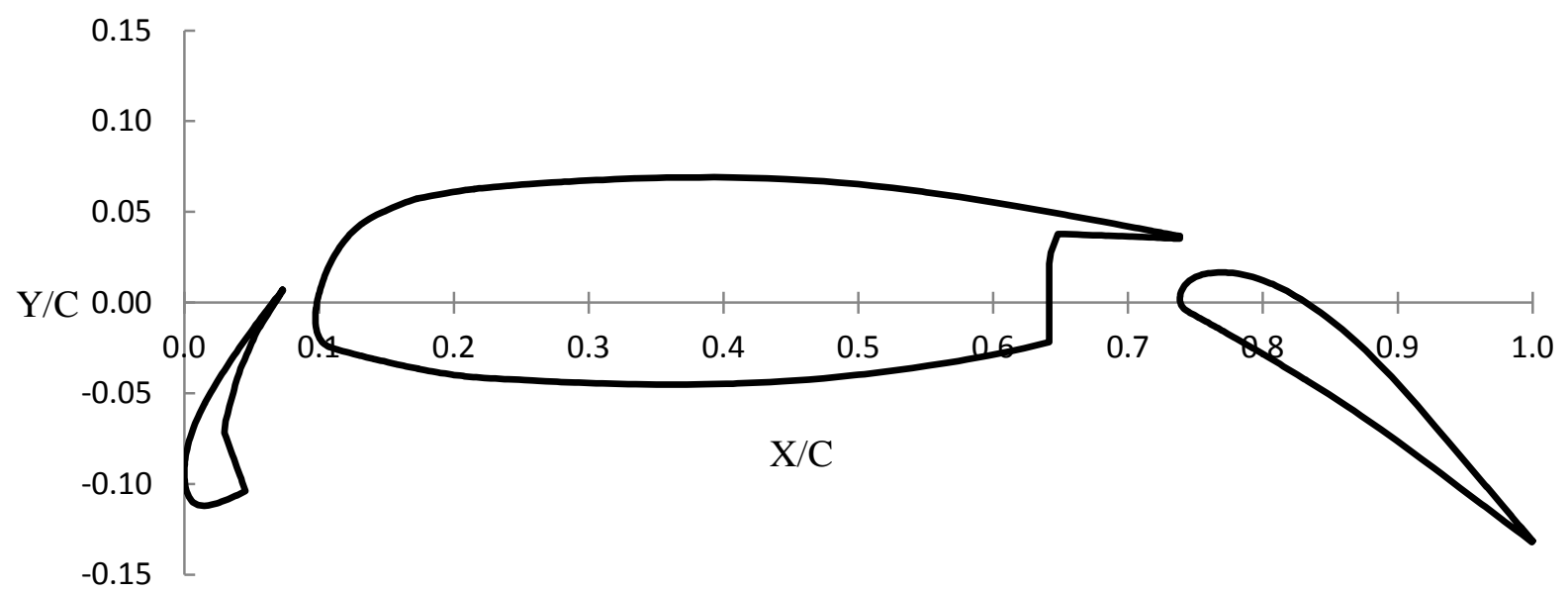

Figure 27.-Trap wing profiles.

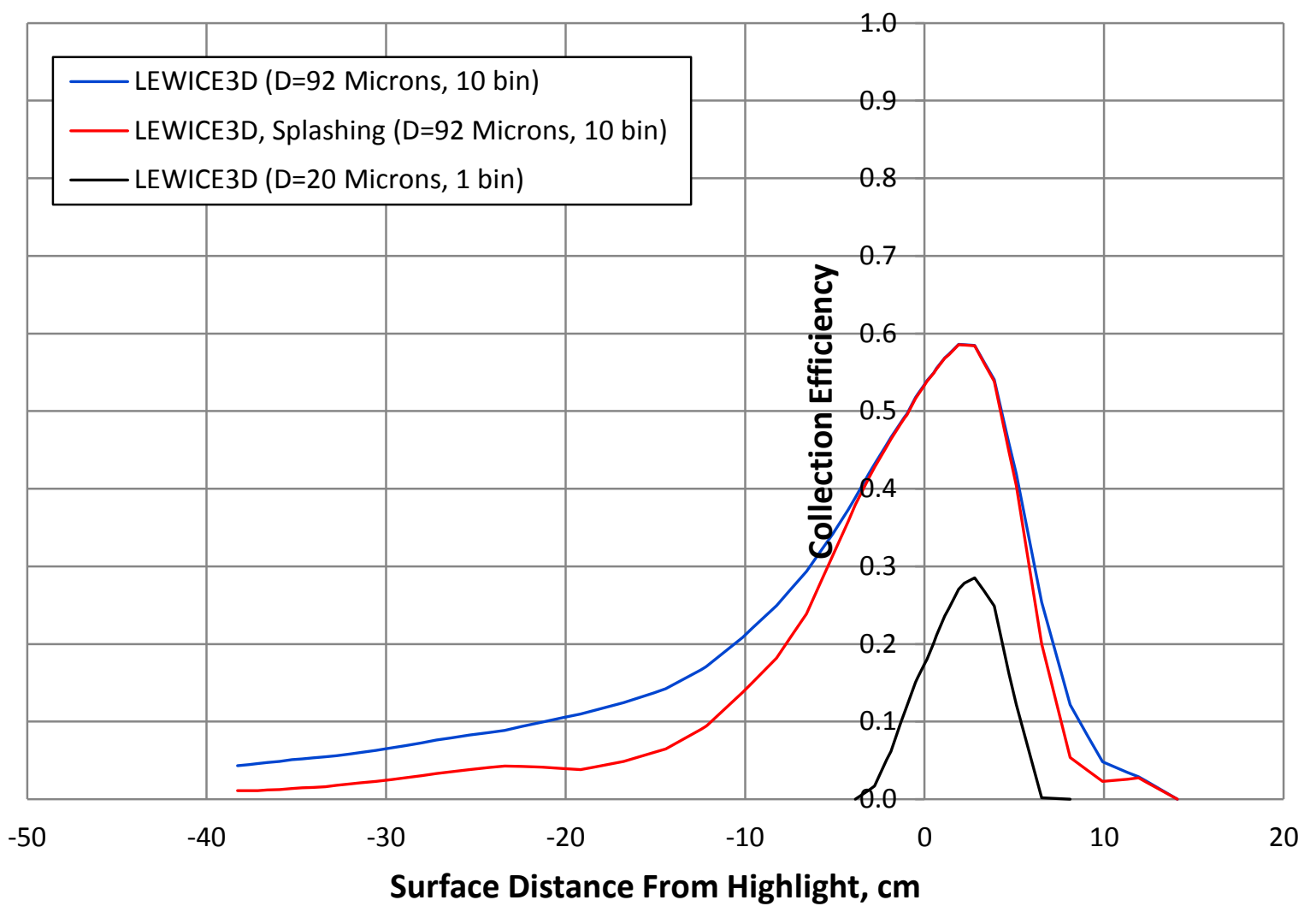

Figure 28.-Collection efficiency results for trap wing slat. 


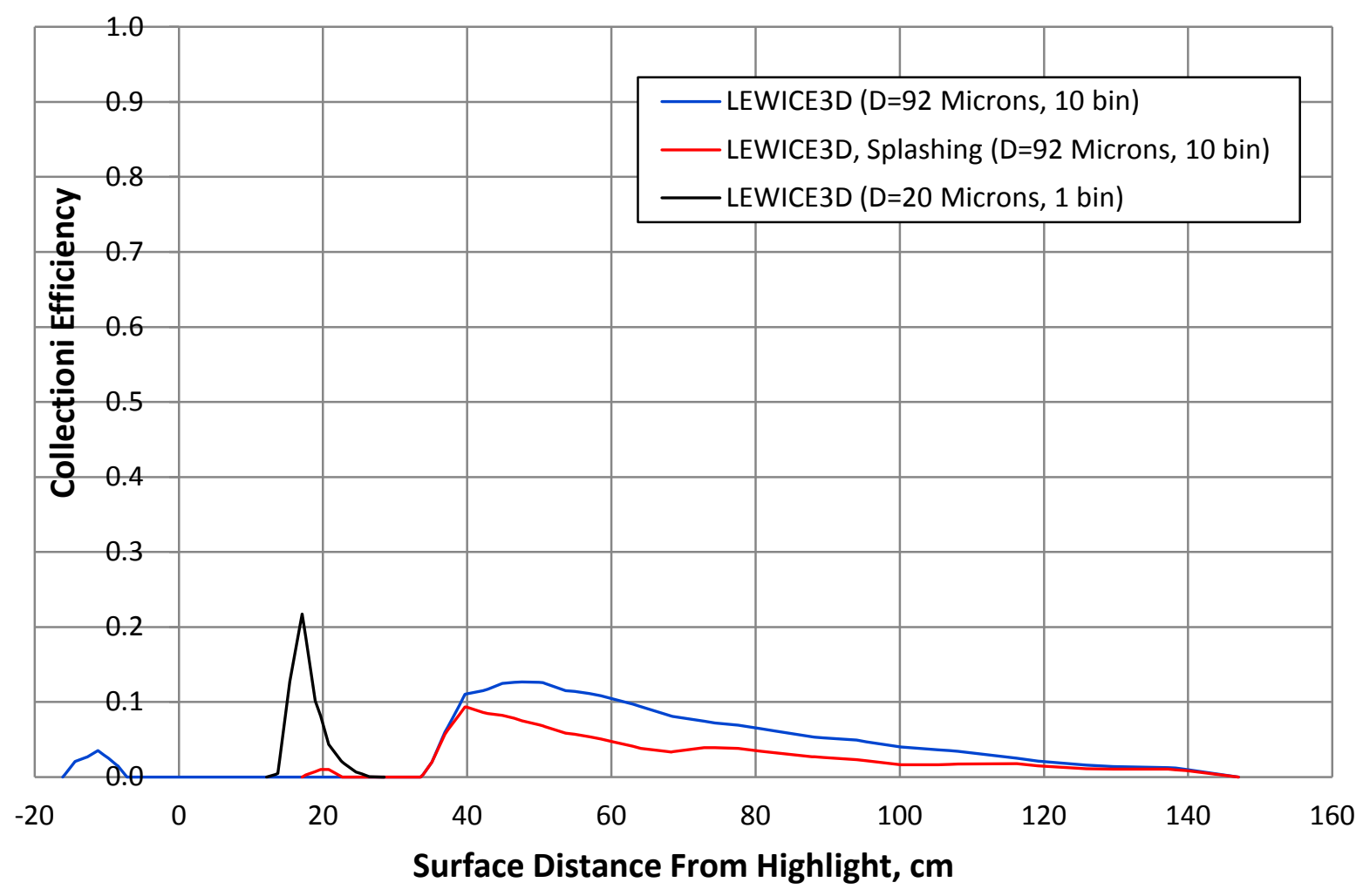

Figure 29.-Collection efficiency results for trap wing main element.

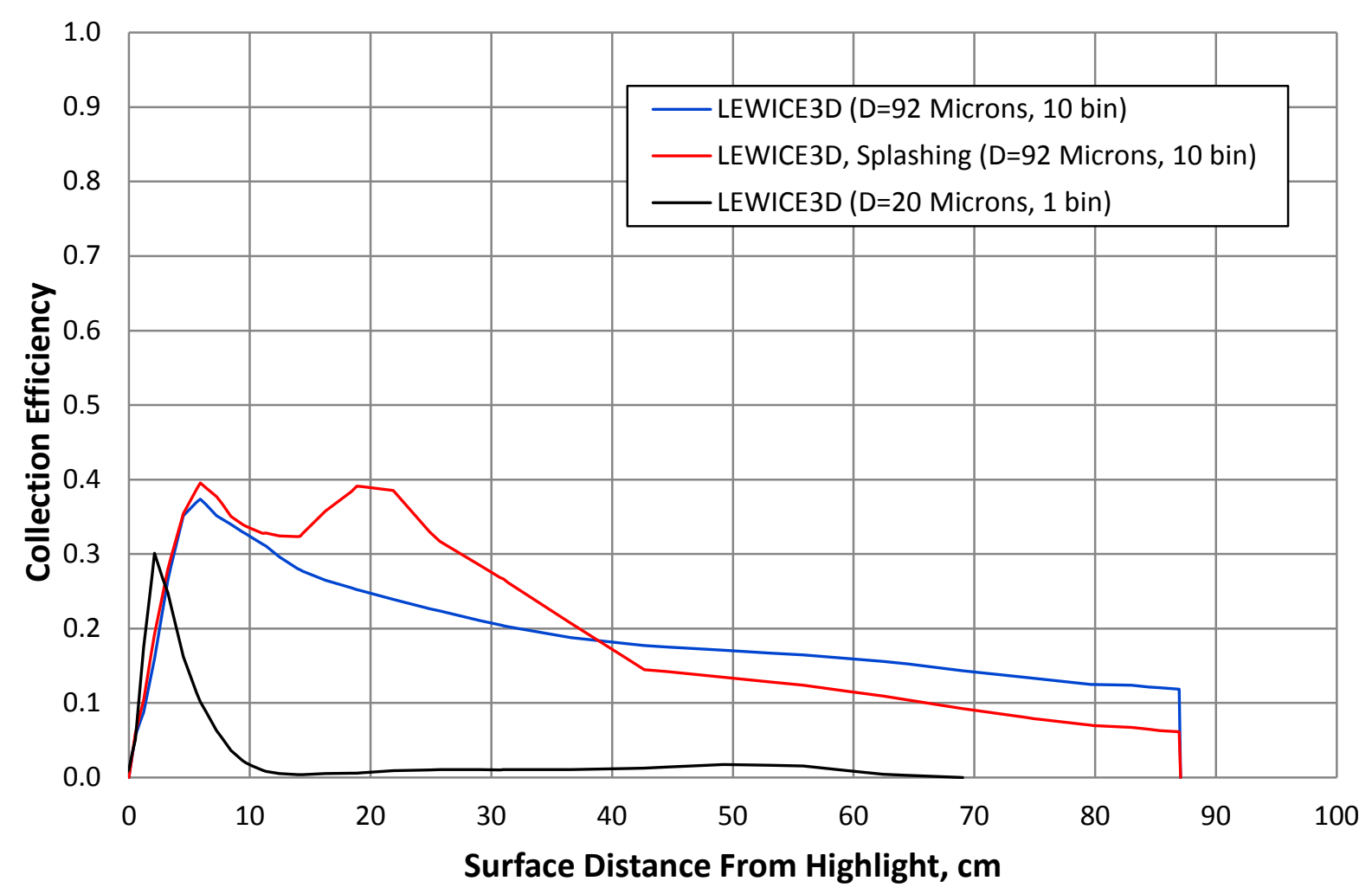

Figure 30.—Collection efficiency results for trap wing flap. 


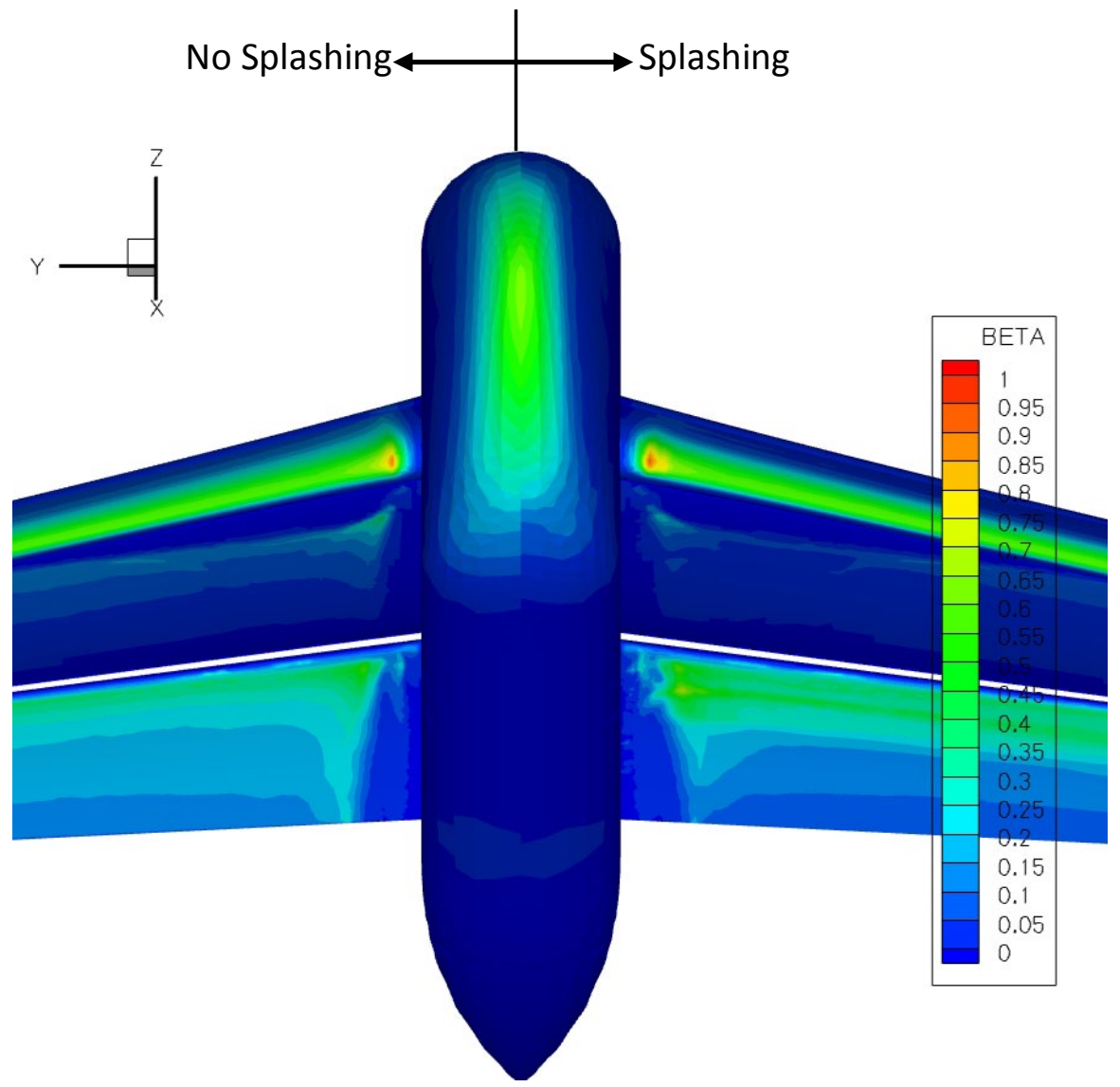

Figure 31.-Collection efficiency results for trap wing.

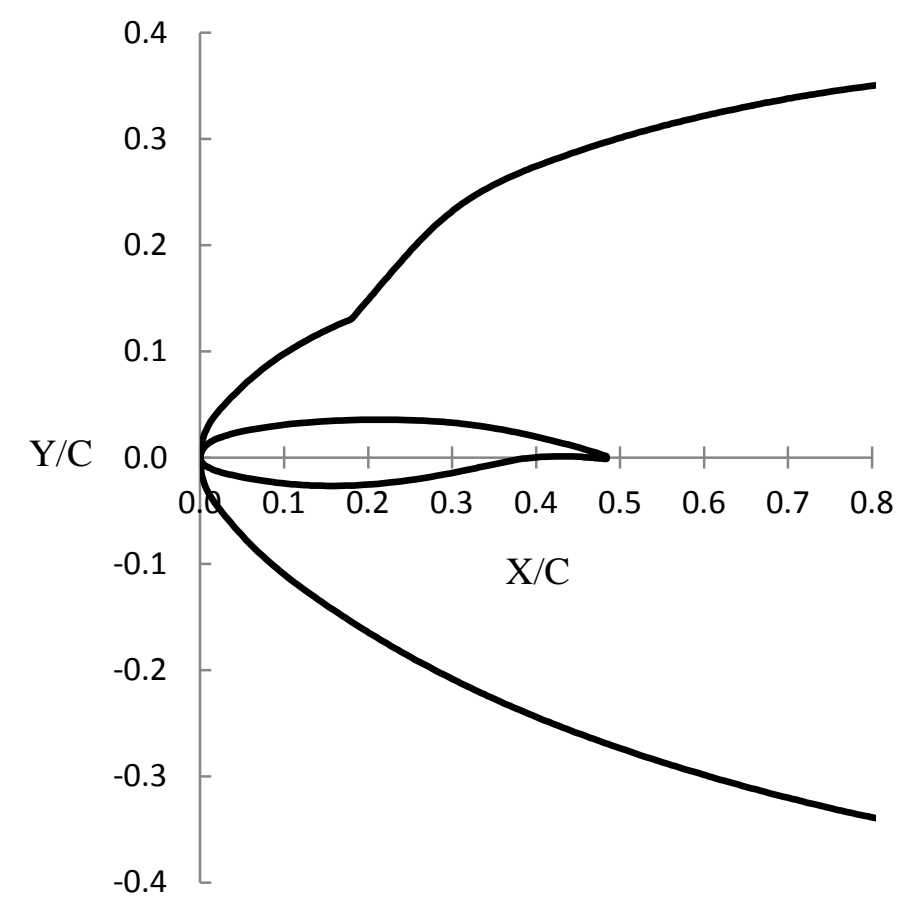

Figure 32.-Geometry profiles for DLR-F4 fuselage centerline and wing. 


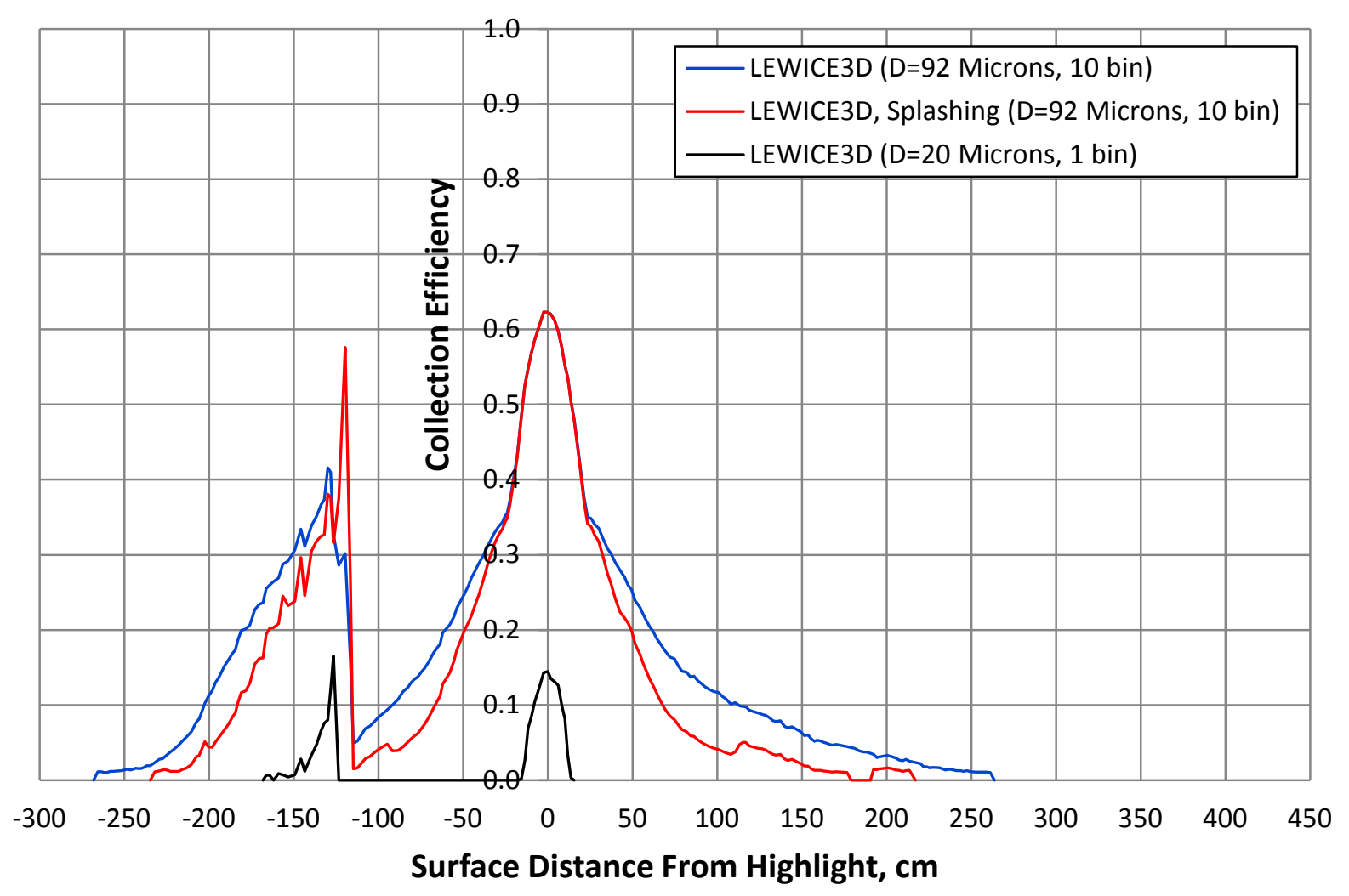

Figure 33.-Collection efficiency results for DLR-F4 fuselage centerline.

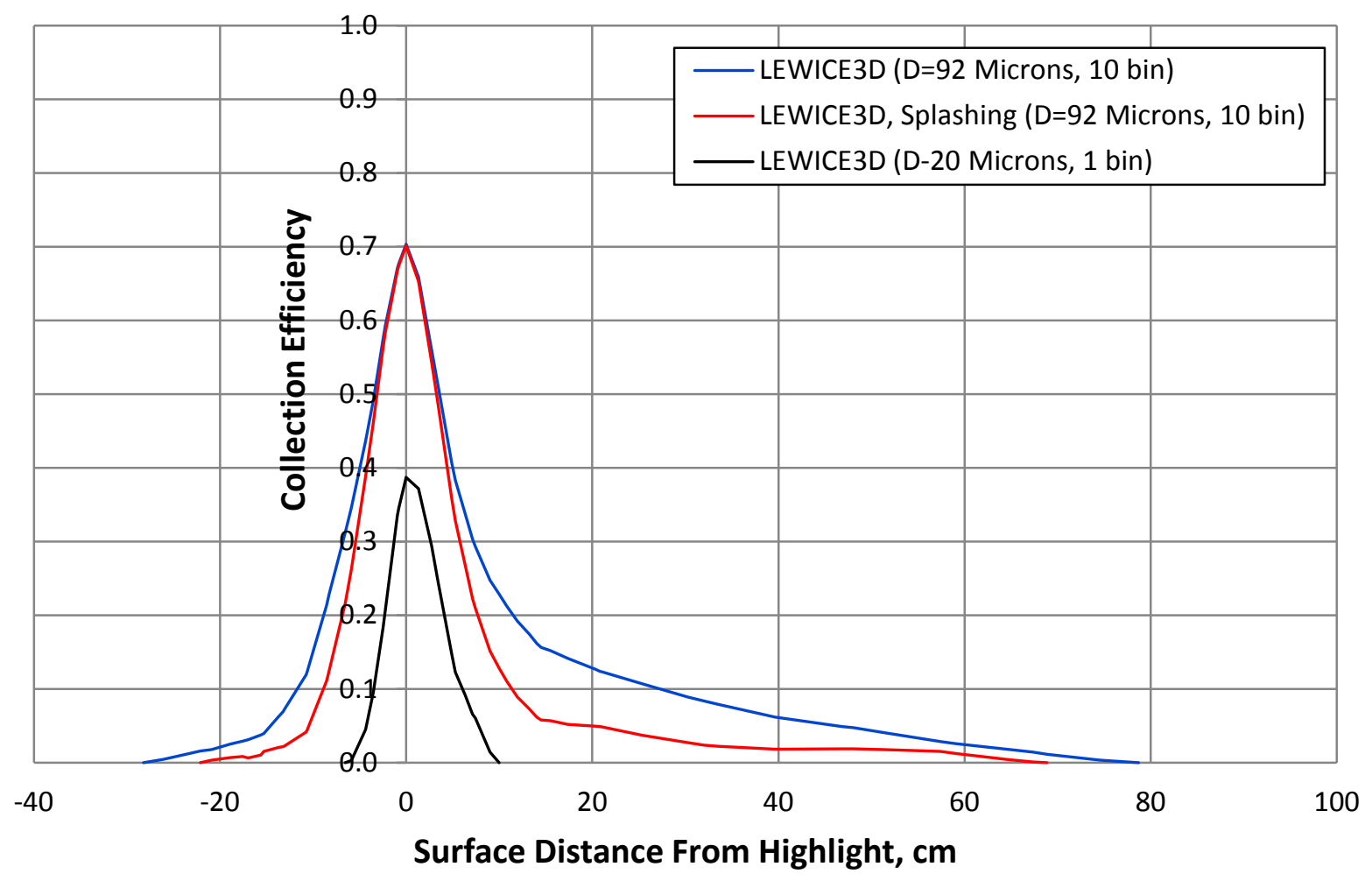

Figure 34.-Collection efficiency results for DLR-F4 wing. 


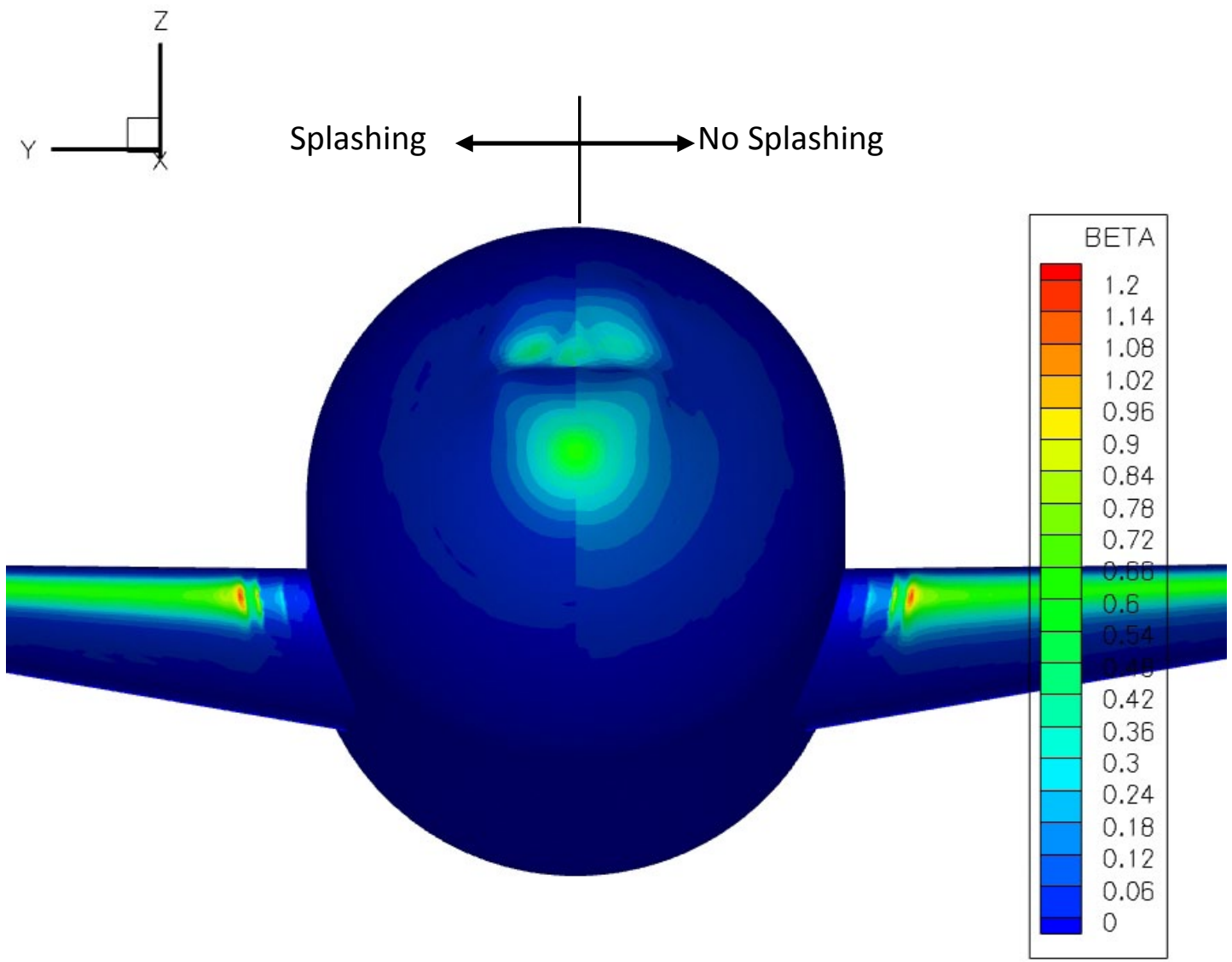

Figure 35.-Collection efficiency results for DLR-F4 Airplane. 


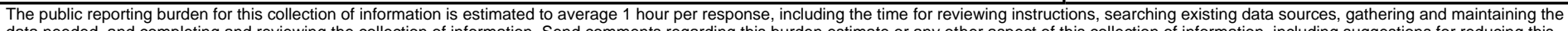

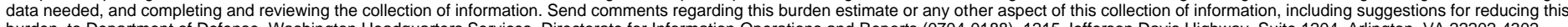

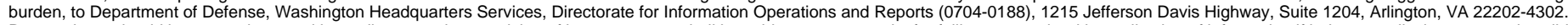

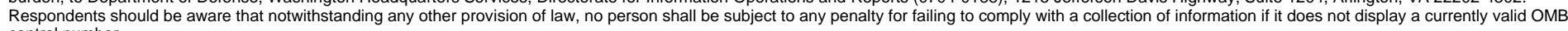

PLEASE DO NOT RETURN YOUR FORM TO THE ABOVE ADDRESS.

\begin{tabular}{l|l|l}
\hline $\begin{array}{l}\text { 1. REPORT DATE (DD-MM-YYYY) } \\
01-10-2011\end{array}$ & $\begin{array}{l}\text { 2. REPORT TYPE } \\
\text { Technical Memorandum }\end{array}$ & 3. DATES COVERED (FrOm - To)
\end{tabular}

4. TITLE AND SUBTITLE

Super Cooled Large Droplet Analysis of Several Geometries Using LEWICE3D Version 3

5a. CONTRACT NUMBER

5b. GRANT NUMBER

5c. PROGRAM ELEMENT NUMBER

6. AUTHOR(S)

Bidwell, Colin, S. 5d. PROJECT NUMBER

5e. TASK NUMBER

5f. WORK UNIT NUMBER

WBS 457280.02.07.03.02.02

7. PERFORMING ORGANIZATION NAME(S) AND ADDRESS(ES)

National Aeronautics and Space Administration

John H. Glenn Research Center at Lewis Field

8. PERFORMING ORGANIZATION

REPORT NUMBER

E-17549

Cleveland, Ohio 44135-3191

9. SPONSORING/MONITORING AGENCY NAME(S) AND ADDRESS(ES)

National Aeronautics and Space Administration

Washington, DC 20546-0001

\section{SPONSORING/MONITOR'S ACRONYM(S) \\ NASA}

11. SPONSORING/MONITORING REPORT NUMBER

NASA/TM-2011-216945

\section{DISTRIBUTIONIAVAILABILITY STATEMENT}

Unclassified-Unlimited

Subject Category: 03

Available electronically at http://www.sti.nasa.gov

This publication is available from the NASA Center for AeroSpace Information, 443-757-5802

\section{SUPPLEMENTARY NOTES}

\section{ABSTRACT}

Super Cooled Large Droplet (SLD) collection efficiency calculations were performed for several geometries using the LEWICE3D Version 3 software. The computations were performed using the NASA Glenn Research Center SLD splashing model which has been incorporated into the LEWICE3D Version 3 software. Comparisons to experiment were made where available. The geometries included two straight wings, a swept 64A008 wing tip, two high lift geometries, and the generic commercial transport DLR-F4 wing body configuration. In general the LEWICE3D Version 3 computations compared well with the 2D LEWICE 3.2.2 results and with experimental data where available.

15. SUBJECT TERMS

Aircraft icing; Droplet splashing; Droplet breakup; Droplet impingement

\begin{tabular}{|c|c|c|c|c|c|}
\hline \multicolumn{3}{|c|}{ 16. SECURITY CLASSIFICATION OF: } & \multirow{2}{*}{$\begin{array}{l}\text { 17. LIMITATION OF } \\
\text { ABSTRACT } \\
\text { UU }\end{array}$} & \multirow{2}{*}{$\begin{array}{l}\text { 18. NUMBER } \\
\text { OF } \\
\text { PAGES } \\
36\end{array}$} & \multirow{2}{*}{$\begin{array}{l}\text { 19a. NAME OF RESPONSIBLE PERSON } \\
\text { STI Help Desk (email:help@sti.nasa.gov) } \\
\text { 19b. TELEPHONE NUMBER (include area code) } \\
\text { 443-757-5802 }\end{array}$} \\
\hline $\begin{array}{l}\text { a. REPORT } \\
\text { U }\end{array}$ & $\begin{array}{l}\text { b. ABSTRACT } \\
U\end{array}$ & $\begin{array}{l}\text { c. THIS } \\
\text { PAGE } \\
\text { U }\end{array}$ & & & \\
\hline
\end{tabular}



